May 1990

\title{
DYNAMIC DUOPOLY WITH LEARNING \\ THROUGH MARKET EXPERIMENTATION
}

\author{
Philippe Aghion* \\ Maria Paz Espinoza** \\ Bruno Jullien***
}

$N^{\circ} 9012$

* DELTA and HEC, Paris

** University of Bilbao

*** CEPREMAP

We are very grateful to Patrick Bolton for many insightful discussions and for his helpful advice. We also wish to thank Richard Caves, Jean-Jacques Laffont, Andreu Mas-Colell, Eric Maskin, Jean-Charles Rochet, Margaret Slade, John Sutton, Jean Tirole, Mike Whinston, anonymous referees and the editor of this journal. 


\section{ABSTRACT \\ Dynamic Duopoly with Learning Through Market Experimentation}

This paper analyzes how learning behaviors can substantially modify the outcome of competition in an oligopolistic industry facing demand uncertainty. We consider the case of a symmetric duopoly game where firms have imperfect information about market demand and learn through observing the volume of their sales. The main body of the paper consists in showing how market experimentation can explain the existence of price dispersion in an oligopolistic industry. We study this phenomenon and its dynamic evolution in the context of a Hotelling duopoly model ; we then extend the analysis to general demand functions, to $\mathrm{N}$-firm oligopolies, to asymmetric duopolies. We evaluate the social cost of price-experimentation by oligopolistic firms and we emphasize several implications of the public good aspect of information about market demand. We then conclude by a few comments on what happens when the value of information in the oligopolistic industry is negative.

Journal of Economic Literature : 022, 026, 610

Key words : Experimentation, Information, Competition.

RESUME

Duopole dynamique avec apprentissage au moyen d'expérimentation par les prix

Le papier montre que la prise en compte de comportements actifs d'apprentissage modifie de façon importante $I^{\prime}$ analyse de la concurrence dans les marchés oligopolistiques. Nous considérons le cas d'un duopole symétrique dans lequel les entreprises ont une information imparfaite sur la fonction de demande et acquièrent de l'information en observant leurs ventes. La partie centrale du papier montre comment l'expérimentation par le marché permet d'expliquer l'existence d'une dispersion des prix dans un marché oligopolistique. Nous étudions ce phénomène et son évolution dynamique dans le contexte du modèle d'Hotelling à deux firmes ; puis nous étendons 1 'analyse à des fonctions de demande générales, au cas d'un oligopole à $n$ firmes, et au cas d'un modèle dissymétrique. Nous évaluons le coût social de l'expérimentation par les prix et mettons en avant plusieurs implications de l'aspect "bien public" de l'information sur la demande de marché. Finallement nous concluons par quelques commentaires sur ce qui peut aboutir quand la valeur de l'information pour l'industrie est négative.

Journal of Economic Literature : $022,026,610$

Mots clefs : Expérimentation, Information, Concurrence 


\section{INTRODUCTION}

In an influential survey of new theoretical developments on competition with imperfect information, Rothschild laid down three requirements for any satisfactory model of price adjustment : "A satisfactory model of adjustment to equilibrium will have at least three parts : a discussion of the rules which market participants follow when the market is out of equilibrium, a description of how a market system in which individuals follow these rules operates, and, of course a convergence theorem"(1) (Rothschild (1973) pp 1285-1286). He then went on and dismissed most existing work for not satisfying all of these criteria : "Most adjustment models have sacrified the first requirement to the second and third" (Rothschild (1973) pp 1286).

Unfortunately, his verdict could be returned again, almost unaltered today, about models of price adjustment with competition. This state of affairs persists largely because of the difficulty of the task set up by Rothschild. (2) Accordingly, the present paper is a partial attempt at developing a theory of price adjustment with competition which meets all of Rothschild's requirements. We propose to circumvent some of the most obvious difficulties arising in this type of problems by modelling out of equilibrium states as situations in which market participants have incomplete information about demand or supply. And we define a long-run equilibrium as a Nash equilibrium in the stage game where all participants have exhausted all valuable learning opportunities from past observations and experimentation about the relevant aspects of demand and supply.

To model adjustment processes as learning by experimentation processes has several advantages, the major one being that the market outcome at every stage of the adjustment process can be modelled as a Nash equilibrium of an incomplete information stage game. The adjustment process is then given by the sequence of Nash-equilibria over time, as the information structure changes through learning by experimentation. Admittedly, we are putting a lot of faith in Nash equilibrium as a solution concept. We have, however, chosen this strategy for lack of any other coherent alternative(3). Our paper is concerned with new important aspects of these adjustment processes. But we do not attempt a full fledged general analysis. This remains, as yet, out of reach.

Thus, most of the paper is concerned with a simple repeated duopoly where firms offer differentiated products and compete in prices. The specific framework we consider is that of horizontal differentiation in a simple Hotelling model. We have chosen to focus on one specific aspect of demand, uncertainty namely that concerning the substitutability of the two products offered by the two firms. As an illustration consider the example of Money-market mutual funds versus interest bearing deposit accounts ; 
when the latter were introduced it probably was not very clear at the outset to what extent they were a close substitute for the traditional bank-deposit accounts. But gradually, through learning by experimentation, the degree of substitutabily of the two financial products became more apparent. The incompleteness of information about the substitutability between the two products in our model is formalized by assuming that firms do not know exactly the "transportation-cost" faced by consumers.

A key insight of our model is that information about this transportation cost is acquired most effectively if firms experiment by setting different prices ; That is, if they disperse their prices. We show that in a symmetric equilibrium, price dispersion is largest when firms' information is weakest and this dispersion gradually declines as firms gather more and more information. It eventually disappears in the long-run equilibrium where firms end up acquiring complete information about the transportation costs of consumers. (4) We thus propose a disequilibrium theory of price dispersion as an alternative to the existing equilibrium price-dispersion theories. (5)

In addition, our simple model illustrates what we believe to be several general aspects of any situation of learning by experimentation by multiple competing firms. To begin with, optimal learning through experimentation with several agents requires that agents take different actions so as to obtain as good a sample of observations as possible. As mentioned above, in our model this sampling motive takes the form of price dispersion. Second, the public-good aspect of individual experimentation creates incentives for free-riding. More precisely, some actions while they yield socially valuable information, also involve high individual cost. ${ }^{(6)}$ Each firm then would like the other firm to bear that cost. In our model, the costly action is to set the highest of the two prices. Hence the existence of a coordination problem between the two experimenting firms. Following Crawford and Haller (1990) who argue that "asymmetric pure strategy equilibria are unconvincing and inappropriate for the study of coordination in games", we select the unique symmetric Nash Equilibrium-which involves mixed strategies whenever firms do experiment to represent the outcome of this coordination game.

A third important aspect of experimentation by several agents is the fact that experimentation by one agent may "garble" the signal received by other agents and thus slow down information accumulation. In our model this "signal-garbling" corresponds to the lack of coordination - mentionned above - between the two duopolists' price behaviors. It turns out that if one firm decided to behave myopically, this coordination problem would be automatically overcome. More precisely, we show in section $\mathrm{V}$ that an experimenting ("farsighted") firm would (weakly) benefit from competing with a myopic firm instead of another farsighted firm. This is a striking 
result, given that the myopic firm free-rides on experimentation costs.

Finally, in the presence of competition, new information about the substitutability of the products may be bad for the firms, since it may exacerbate competition and lead to the dissipation of duopoly profits. We show indeed that in some situations the value of information is negative ; moreover we show that the fear of discovering "bad" information can be a good disciplining device for firms to be less aggressive competitors. (7)

To our knowledge, the theoretical literature on the subject is almost non-existant. The exceptions are : Cyert and Degroot (1971) who develop a model of duopoly in which a leader firm learns about its rival's behavior from market data. Because of the sequential structure of the model, their analysis comes closest to the case of an experimenting monopoly ; Kirman (1985), who studies the convergence properties of a model where competing firms learn the demand characteristics through time. (This analysis however is conducted for the case of non-experimenting firms using non-bayesian econometric estimation procedures) ; Riordan (1985), who has emphasized strategic manipulation by competing firms of the information revealed through market data, in models of signal jamming.

The paper is organised as follows. Section I describes the model and the equilibrium concept. Section II derives the price dispersion result. Section III establishes the robustness of this result to having more general demand schedules, to increasing the number of oligopolistic firms, and to introducing small asymmetries between firms' demands or costs. Section IV studies the dynamics of price dispersion in a T-period extension of the model. Section $V$ compares the previous results with the situation where only one firm experiments. Section VI is devoted to welfare analysis. Finally section VII concludes by investigating the possibility and the consequences of a negative value of information, and it clarifies the relationship between the notions of value of information and value of price discrimination. 


\section{The basic mode1}

We consider a two-period Hotelling model in which two firms, $A$ and $B$, located at the extreme points of the interval $[0,1]$, costlessly produce two goods $A$ and $B$ that are identical except for their location ; these two firms compete in mill price and cannot change location. Consumers are uniformly distributed on the same interval $[0,1]$ and each of them purchases only one unit of good per period, provided the total payment (mill price plus transportation cost) is less than his/her reservation value $R$. The goods cannot be stored by consumers between period 1 and period 2 and the cost of transporting one unit of good is $1 / \theta$ per unit of distance.

At the beginning of period 1, both firms ignore the exact value of $\theta$. On the other hand this value is known by consumers who directly bear the transportation costs. ${ }^{(8)}$ However firms $A$ and $B$ initially share the same prior beliefs about $\theta$, namely :

$$
\theta=\left\{\begin{array}{l}
\bar{\theta} \text { with probability } 1-q_{0} \\
\underline{\theta} \text { with probability } q_{0}, \text { where } \underline{\theta}<\bar{\theta} \leqslant 2 \underline{\theta}^{(9)} .
\end{array}\right.
$$

These priors are common knowledge.

Except in Section 7 below, we shall assume that $R$ is sufficiently large for the whole market (whose size is equal to 1 ) to be served by firms $A$ and $B$; i.e, none of these firms behaves as a local monopolist. Thus, if $p_{A}$ and $p_{B}$ denote the prices currently charged by firm $A$ and firm $B$, respectively, the deterministic parts of the demands faced by these two firms are given by :

$$
\left\{\begin{array}{l}
D_{A}\left(p_{A}, p_{B}, \theta\right)=\frac{1}{2}+\frac{p_{B}-p_{A}}{2} \cdot \theta \\
D_{B}\left(p_{A}, p_{B}, \theta\right)=\frac{1}{2}+\frac{p_{A}-p_{B}}{2} \cdot \theta
\end{array}\right.
$$

Let $\tilde{\mathrm{X}}_{\mathrm{A}}$ and $\tilde{\mathrm{X}}_{\mathrm{B}}$ denote the current observed demands for product $\mathrm{A}$ and $B$ respectively. Even though total demand $\left(\tilde{X}_{A}+\tilde{X}_{B}\right)$ is fixed at $1^{(10)}$, there is some uncertainty on how this aggregate demand is distributed between the two duopolists. This uncertainty can be due to the fact that some consumers make mistakes and end up in the wrong store, or to unexpected changes in their tastes that make them prefer, say, firm A to firm B, even though it would be cheaper to purchase from B. More formally : 


$$
\left\{\begin{array}{l}
\tilde{\mathrm{X}}_{\mathrm{A}}=\mathrm{D}_{\mathrm{A}}\left(\mathrm{p}_{\mathrm{A}}, \mathrm{p}_{\mathrm{B}}, \theta\right)+\tilde{\epsilon} \\
\tilde{\mathrm{X}}_{\mathrm{B}}=\mathrm{D}_{\mathrm{B}}\left(\mathrm{p}_{\mathrm{A}}, \mathrm{p}_{\mathrm{B}}, \theta\right)-\tilde{\epsilon}
\end{array}\right.
$$

where $D_{A}$ and $D_{B}$ are given by (1), and $\tilde{\epsilon}$ is a random variable uniformly distributed on the interval $\left[-\frac{\tilde{\epsilon}}{2}, \frac{\tilde{\epsilon}}{2}\right]=I$, with $0 \leqslant \tilde{\epsilon} \leqslant 1$.

\section{$\overline{\text { Insert Figure } 1}$}

The timing of the game is as follows (Figure 1):

At the beginning of period 1 , each firm $i=A, B$ has to set a price $p_{1}$ on the basis of its prior beliefs about the value of parameter $\theta$. Then, first-period demands $\tilde{\mathrm{x}}_{\mathrm{A}}$ and $\tilde{\mathrm{X}}_{\mathrm{B}}$ are realized. We assume that both firms observe the pair of first-period prices $\left(p_{A}, p_{B}\right)$ and sales realizations $\tilde{\mathrm{x}}_{\mathrm{A}}, \tilde{\mathrm{X}}_{\mathrm{B}} \cdot{ }^{(11)}$

At the beginning of period 2, firms will revise their prior beliefs about $\theta$ on the basis of past observations $\left(X_{A}, X_{B}, p_{A}, p_{B}\right)$. This information acquired in period 1 is processed using Bayes law and thus transformed into a posterior probability distribution $(q, 1-q)$, where :

$$
q=\operatorname{Proba}\left(\theta=\underline{\theta} / x_{A}, x_{B}, p_{A}, p_{B}\right) .
$$

In this basic model where $\theta$ can only take two values, the posterior probability is simply given by : $q=0,1$, or $q_{0}$, depending on whether firms have learned that $\theta=\vec{\theta}$, that $\theta=\underline{\theta}$, or have remained uninformed about $\theta$. Finally, on the basis of their posterior beliefs about $\theta$, firms $A$ and $B$ will choose second-period prices $p_{A}^{2}$ and $p_{B}^{2}$.

Our equilibrium concept will be Perfect Bayesian Equilibrium (PBE), so that a natural way of deriving the equilibria of the two-period duopoly game we have just described, is through backward induction starting from period $t=2$.

The subgame starting at date $t=2$ is easy to solve. Firms simply play the one-shot Hotelling game with common posterior beliefs $\mathrm{q} \in\left\{0,1, \mathrm{q}_{0}\right\}$. This symmetric game has a unique Nash (Bayesian) Equilibrium, corresponding to the following second-period payoff for both firms ${ }^{(12)}$ :

$$
\pi(q)=\frac{1}{2} \cdot \frac{1}{E(\theta / q)}=\frac{1}{2} \cdot \frac{1}{q \underline{\theta}+(1-q) \bar{\theta}}
$$

It follows from (3) that information about $\theta$ is positively valued 


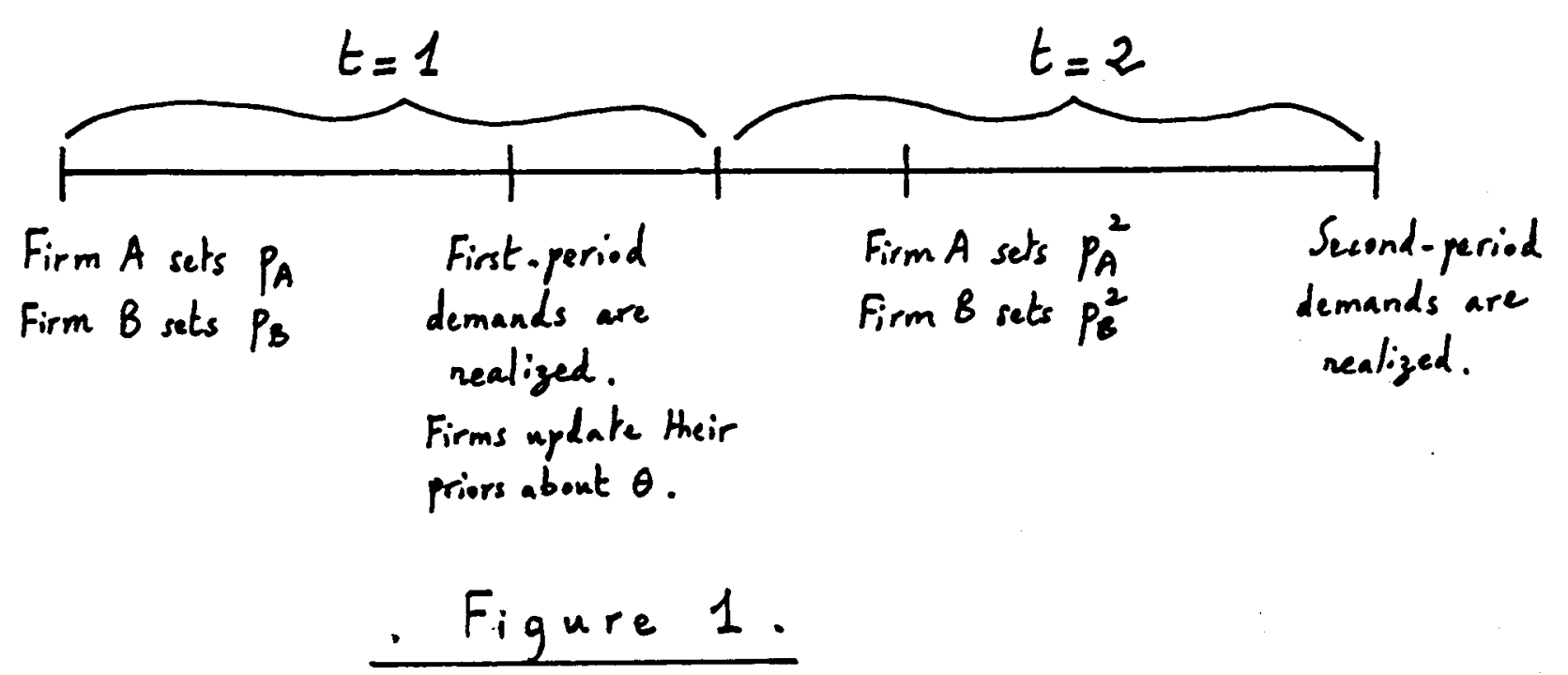


by both firms ex-ante. To see this, it suffices to compare between firms' expectations of second-period profits as of period 1, respectively when the true value of $\theta$ is to be learnt between period 1 and period 2 and when it isn't. In the first "informed" case, expected second-period profits will be equal to :

$$
\pi_{1}=q_{0} \cdot \pi(1)+\left(1-q_{0}\right) \cdot \pi(0)
$$

In the second "uninformed" case, expected second-period profits will simply be :

$$
\pi_{u}=\pi\left(q_{0}\right)
$$

Since $\pi(q)$ is convex in $q$, we have indeed : $V=\pi_{i}-\pi_{u}>0$. We shall refer to $V$ as the value of information. As long as this value is positive, both firms will face a fundamental trade-off between maximizing short-run expected payoffs (i.e $E_{\theta}\left(p_{A} \cdot D\left(p_{A}, p_{B}, \theta\right)\right.$ ) for firm $A$ ) and maximizing the informational content of first-period price strategies (i.e $\left.E_{\theta}\left(\pi(q) / q_{0}, p_{A}, p_{B}\right)\right)$. This trade-off would naturally disappear if firms were myopic, in which case they would simply choose first-period prices so as to maximize short-run expected profits. In that case, the ${ }_{1}^{\text {unique }}$ Nash-equilibrium would be symmetric in prices (with $\left.p_{A}=p_{B}=\frac{1}{E\left(\theta / q_{0}\right)}\right)$, i.e, given (1), totally uninformative about $\theta$.

This implies that whenever firms are non-myopic, they will be willing to sacrifice part of their short-run profits in order to acquire valuable information about $\theta$ in period 2 .

The total profits expected by firm $A$ in period 1 are given by :

$$
\pi_{A}\left(p_{A}, p_{B}\right)=E_{\theta}\left(p_{A} \cdot D\left(p_{A}, p_{B}, \theta\right)\right)+\delta \cdot E_{\theta}\left(\pi(q) / q_{0}, p_{A}, p_{B}\right),
$$

where $\delta \in[0,1]$ is the firms' common discount factor. Total expected profits for firm $B$ (which we denote by $\pi_{B}\left(p_{A}, p_{B}\right)$ ) are similarly defined.

A first-period price-equilibrium $\left(\mathrm{p}_{\mathrm{A}}^{*}, \mathrm{p}_{\mathrm{B}}^{*}\right)$ will be simply defined as a Nash-equilibrium of the reduced game $G=\left\{\mathbb{R}_{+} \times \mathbb{R}_{+}, \pi_{A}(\ldots), \pi_{B}(\ldots)\right\}$. 


\section{The "sampling effect" of learning}

In this section we shall completely solve the duopoly game G. In particular we will prove that, whenever $\delta \neq 0$, all equilibria of that game involve price-dispersion in period 1. This result is not surprising in the context of the model introduced in Section 1, where the only way for firms to acquire information about $\theta$ is by setting different prices $p_{A} \neq p_{B}$. However we shall argue about the generality of this price-dispersion result in the next section.

The first step is to describe the inference process followed by firms $A$ and $B$ once they have observed first-period data $\left(p_{A}, p_{B}, \tilde{X}_{A}, \tilde{X}_{B}\right)$, so as to derive an expression for expected second-period profits as a function of first-period prices $\left(\mathrm{p}_{A}, \mathrm{p}_{B}\right)$. Firms' information can be summarized by $\tilde{x}_{A}=D\left(p_{A}, p_{B}, \theta\right)+\tilde{\epsilon}$, where $\theta$ and $\tilde{\epsilon}$ are unknown. Two cases must be distinguished :

(a) either firms do not infer any information about $\theta$ from observing the realization of their sales. This will be the case, in the situation described by figure 2, if and only if :

$$
\tilde{\mathrm{X}}_{\mathrm{A}} \in\left[\mathrm{D}\left(\mathrm{p}_{\mathrm{A}}, \mathrm{p}_{\mathrm{B}}, \bar{\theta}\right)-\bar{\epsilon} / 2, \mathrm{D}\left(\mathrm{p}_{\mathrm{A}}, \mathrm{p}_{\mathrm{B}}, \underline{\theta}\right)+\bar{\epsilon} / 2\right] \text {. }
$$

(b) otherwise firms will necessarily learn the exact value of parameter $\theta$.

\section{$\overline{\text { Insert Figure 2 }}$}

The probability, evaluated ex-ante, of firms learning the true value of $\theta$ given first-period prices $p_{A}, p_{B}$, will then simply be equal to :

$$
\min \left(1, \frac{\left|\mathrm{D}\left(\mathrm{p}_{\mathrm{A}}, \mathrm{p}_{\mathrm{B}}, \bar{\theta}\right)-\mathrm{D}\left(\mathrm{p}_{\mathrm{A}}, \mathrm{p}_{\mathrm{B}}, \underline{\theta}\right)\right|}{\bar{\epsilon}}\right)
$$

i.e, from (1) in section 1 :

$$
\min \left(1, \frac{\Delta \theta}{2 \bar{\epsilon}}\left|p_{A}-p_{B}\right|\right) \text {, where } \Delta \theta=\bar{\theta}-\underline{\theta} .
$$

In particular this probability is zero whenever $p_{A}=p_{B}$ and it is an increasing linear function of the degree of price-dispersion $\left|p_{A}-p_{B}\right|$ in the neighbourhood of any diagonal point $\left(p_{A}, p_{B}\right)=(p, p)$. 


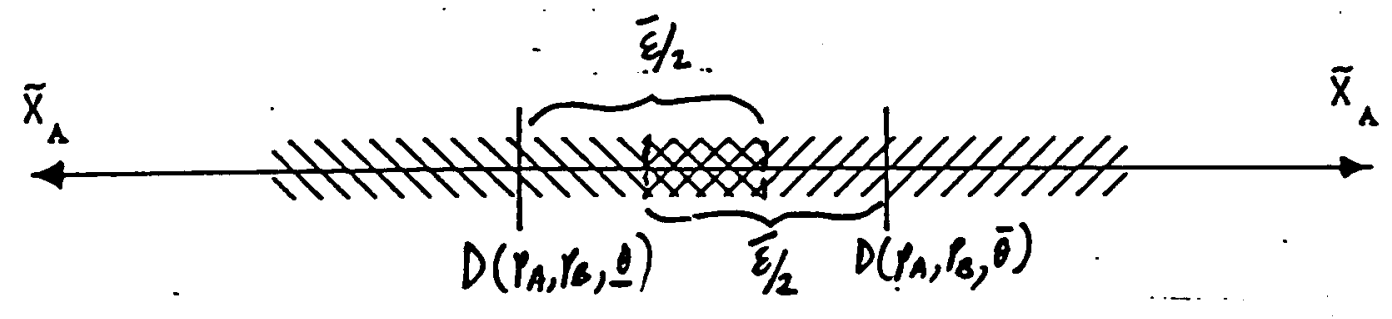

Figure 2. 
So is the expected value of second-period profits, which we can rewrite as :

$$
E_{\theta}\left(\pi(q) / p_{A}, p_{B}\right)=\pi_{u}+\min \left(1, \frac{\Delta \theta}{2 \bar{\epsilon}}\left|p_{A}-p_{B}\right|\right) \cdot\left(\pi_{i}-\pi_{u}\right)
$$

First-period profit maximization would induce firms to set the same price $p_{A}=p_{B} ;$ however, due to the fact that second-period expected profits are linearly increasing in $\left|p_{A}-p_{B}\right|$ around any diagonal point $p_{A}=p_{B}$, there is a first-order gain for firms to price-disperse. For $\left|p_{A}-p_{B}\right|$ small, such gain dominates the second-order loss, in terms of short-run profits, of price-dispersing. We can then establish :

\section{Proposition 1 :}

in pure strategies.

In the game with learning $G$, there exist no symmetric equilibrium

Proof : We refer for details to Appendix A, where the best response correspondances for firm $A$ and firm $B$ are explicitly derived. In particular we show that both correspondances never cross the diagonal : firm $A^{\prime} s$ (respectively firm $B^{\prime} s$ ) correspondance has a discontinuity at $p_{B}=\frac{1}{E(\theta)}$ (respectively at $p_{A}=1 / E(\theta)$ ), illustrated by figure 3. Proposition 1 follows then immediately.

Insert Figure $3: p_{B}=1 / E(\theta)$

In particular, we can easily compute the equilibria of the learning game $G$ in numerical examples such as the following one, illustrated by Figure 4 .

Example :

Then we have :

$$
\begin{aligned}
& \bar{\theta}=\frac{4}{3} ; \underline{\theta}=\frac{2}{3} ; \bar{\epsilon}=\frac{1}{4} ; \mathrm{q}_{0}=\frac{1}{2} \\
& \Delta \theta=\frac{2}{3}, \quad \mathrm{~V}=\frac{1}{2}\left\{\mathrm{E}\left(\frac{1}{\theta}\right)-\frac{1}{E(\theta)}\right\}=\frac{1}{16}
\end{aligned}
$$

\section{Insert Figure 4}

In this example there are two equilibria in pure strategies :

$$
\begin{aligned}
& \left(\mathrm{p}_{\mathrm{A}}, \mathrm{p}_{\mathrm{B}}\right)_{1}=\left(1+\frac{\delta}{18}, 1-\frac{\delta}{18}\right) \\
& \left(\mathrm{p}_{\mathrm{A}}, \mathrm{p}_{\mathrm{B}}\right)_{2}=\left(1-\frac{\delta}{18}, 1+\frac{\delta}{18}\right)
\end{aligned}
$$




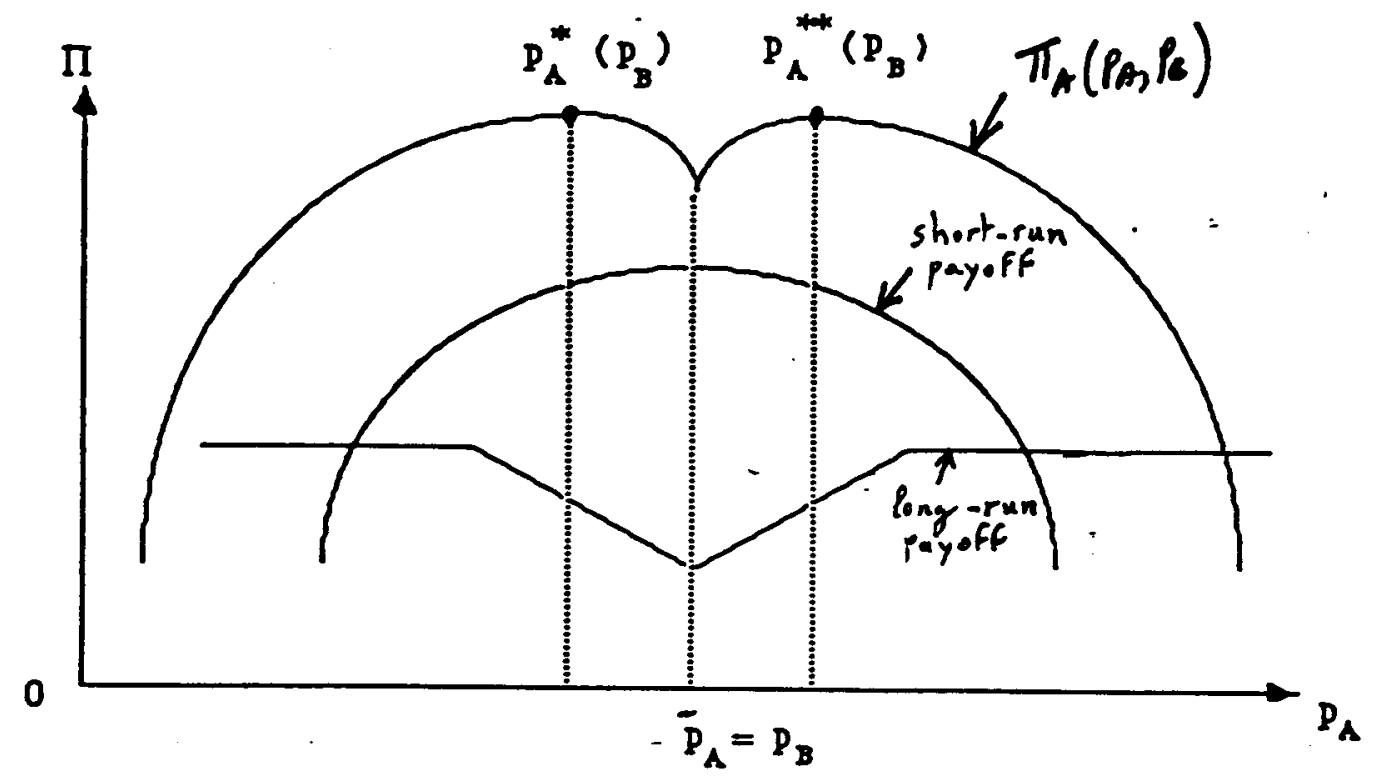

- Figure 3 $=P_{B}=1 / E(\theta)-$

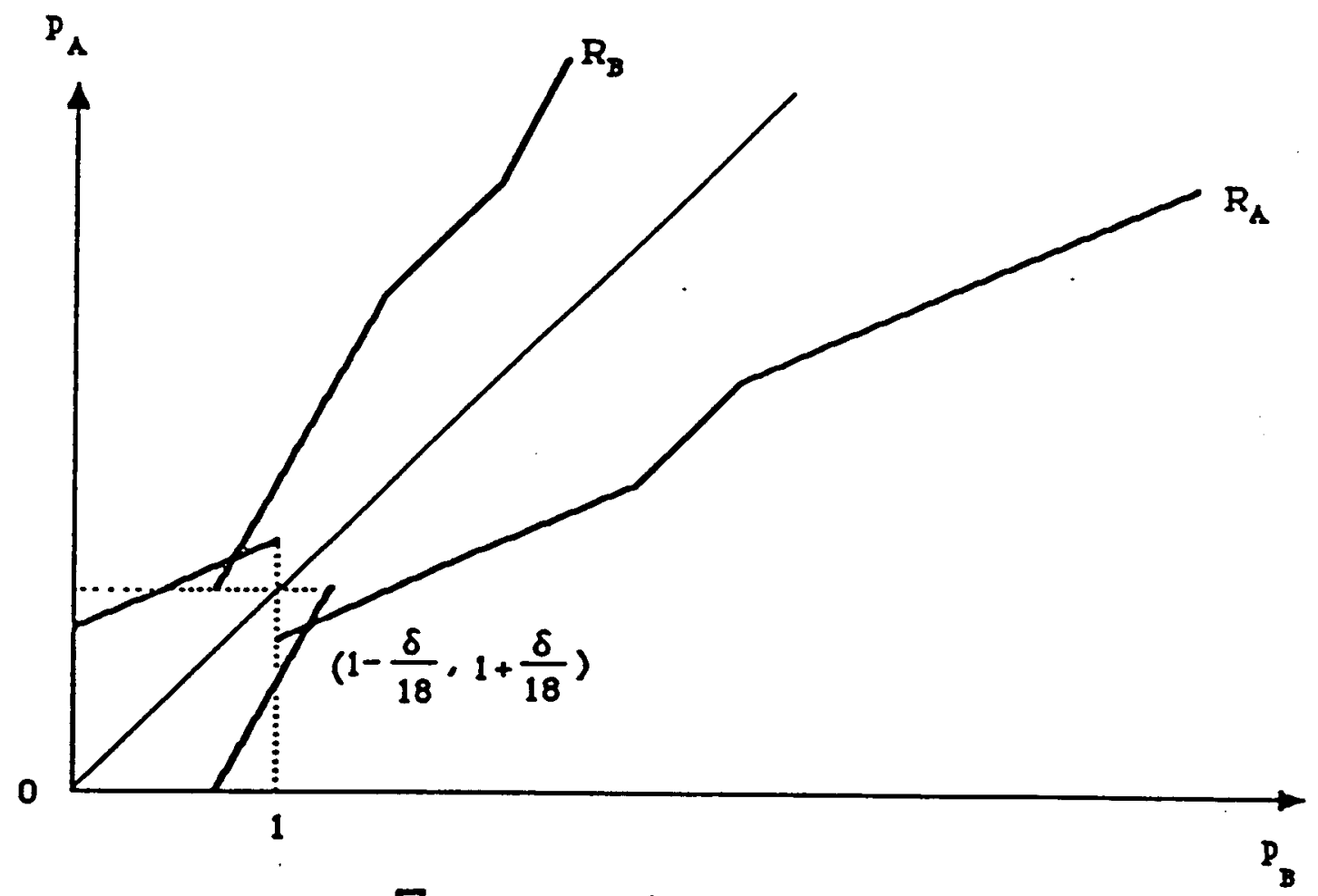

Figure 4. 
The following pair of price distributions is the unique equilibrium in mixed strategies :

$$
F_{A}\left(p_{A}\right)=F_{B}\left(p_{B}\right) \text { uniform on }\left[1-\frac{\delta}{12}, 1+\frac{\delta}{12}\right]
$$

To characterize the equilibria of $G$ in the general case, turns out to be far more complicated. (See Appendix for a detailed analysis.)

However, one can prove the following :

\section{Proposition 2 :}

The learning game $G$ has a unique symmetric Nash equilibrium, in mixed strategies, with both $\mathrm{p}_{A}$ and $\mathrm{p}_{B}$ (first-period prices) distributed on the same compact interval. This interval is centered at $1 / E(\theta)$ [i.e at the one-shot Nash equilibrium level] ; and its diameter -which measures the average degree of price-dispersion in period 1- is an increasing function of the value of information $V$, and of the discount factor $\delta$, it is increasing with $\bar{\epsilon}$ when it is small, decreasing when it is large.

Proof : see appendix.

This result is intuitive : the higher the value of information $V$, the more incentives firms have to price-experiment in period 1. Similarly the higher $\delta$, the more firms will value future expected profits and the more they will be ready to sacrifice in terms of short-run profits in order to acquire better information about $\theta$. The effect of $\frac{\bar{\epsilon}}{\Delta \theta}$ is more ambiguous. The basic intuition is that the higher the ratio $\frac{\bar{\epsilon}}{\Delta \theta}$ the more firms will have to price-disperse in order to infer the true value of $\theta$. However when $\frac{\bar{\epsilon}}{\Delta \theta}$ is too large, information becomes so costly to acquire that firms give up on information acquisition; they emphasize short-run profits maximisation with a resulting decrease in the equilibrium level of price-dispersion.

\section{Robustness of the price-dispersion result}

In this section we analyze the robustness of the price-dispersion result stated in Proposition 1. First, we extend our analysis to more general demand functions than the one derived in the Hotelling context. In particular we consider the case where aggregate demand is both affected by the unknown parameter $\theta$ and subject to random perturbations. Second, we generalize Proposition 1 to the case of $N \geqslant 2$ oligopolistic firms and we study the asymptotic behavior of first-period equilibrium prices when $\mathrm{N}$ tends to infinity.Finally, we briefly discuss what happens when we introduce a small asymmetry between the duopolistic firms. 


\section{(a) More general demand functions}

We first consider the case where two duopolists $A$ and $B$ face the following symmetric demands for their products at each period $t=1,2$ :

and

$$
\tilde{\mathrm{X}}_{\mathrm{A}}=\mathrm{D}\left(\mathrm{p}_{\mathrm{A}}, \mathrm{p}_{\mathrm{B}}, \theta\right)+\tilde{\epsilon}_{\mathrm{a}}+\tilde{\epsilon}_{\mathrm{s}}
$$

where :

$$
\tilde{\mathrm{X}}_{\mathrm{B}}=\mathrm{D}\left(\mathrm{p}_{\mathrm{B}}, \mathrm{p}_{\mathrm{A}}, \theta\right)+\tilde{\epsilon}_{\mathrm{a}}-\tilde{\epsilon}_{\mathrm{s}}
$$

* $\left(p_{A}, p_{B}\right)$ are the prices charged by firms $A$ and $B$ during the current period.

* $\theta$ is an unknown parameter which is fixed for the two periods and can take only two values : $\underline{\theta}<\bar{\theta}$. Both firms initially share the same priors about $\theta$, namely : proba $(\theta \underline{\theta})=q_{0}$.

* $\left(\tilde{\epsilon}_{\mathrm{a}}, \tilde{\epsilon}_{\mathrm{s}}\right)$ is a random shock on demand. The aggregate component $\tilde{\epsilon}_{\mathrm{a}}$ is interpreted as a shock on total demand and reflects all the random influences that affect both firms equally (for example, random changes in consumers'income). This component was equal to zero in the Hotelling case analysed in the previous section. The other component $\tilde{\epsilon}_{\mathbf{s}}$ is interpreted as a shift of market share from one firm to the other which leaves total demand unchanged. For simplicity we assume that $\tilde{\epsilon}_{\mathrm{a}}$ and $\tilde{\epsilon}_{\mathrm{s}}$ are independantly and uniformly distributed, respectively on $\left[-\frac{\hat{\epsilon}}{2}, \frac{\hat{\epsilon}}{2}\right]$ and $\left[-\frac{\bar{\epsilon}}{2}, \frac{\bar{\epsilon}}{2}\right]^{(13)}$.

Now, the reasoning is similar to the one developed in the above section II : suppose that firms $A$ and $B$ have respectively chosen $p_{A}$ and $p_{B}$ in period 1 and that they observe the volumes of sales $\tilde{X}_{A}$ and $\tilde{X}_{B}$ at the end of that period. Then, as in the previous section, two cases must be distinguished.

(a) either firms do not infer any information about $\theta$ from observing $\tilde{\mathrm{X}}_{\mathrm{A}}$ and $\tilde{\mathrm{X}}_{\mathrm{B}}$. This will be the case if and only if the vector $\left(\tilde{\mathrm{X}}_{\mathrm{A}}, \tilde{\mathrm{X}}_{\mathrm{B}}\right)$ belongs to the shaded region in Figure 5 below.

(b) otherwise firms will learn the true value of $\theta$.

The ex-ante probability of firms not learning $\theta$ given first-period prices $\left(p_{A}, p_{B}\right)$ can then be shown to be equal to : 


$$
\left(1-\frac{\left|\Delta D_{B}+\Delta D_{A}\right|}{2 \hat{\epsilon}}\right)\left(1-\frac{\left|\Delta D_{B}-\Delta D_{A}\right|}{2 \bar{\epsilon}}\right)
$$

whenever this expression is positive, where

$$
\Delta \mathrm{D}_{A}\left(\operatorname{resp} . \Delta \mathrm{D}_{B}\right)=D\left(\mathrm{p}_{\mathrm{A}}, \mathrm{p}_{\mathrm{B}}, \bar{\theta}\right)-D\left(\mathrm{p}_{\mathrm{A}}, \mathrm{p}_{\mathrm{B}}, \underline{\theta}\right)\left(\operatorname{resp} . \mathrm{D}\left(\mathrm{p}_{\mathrm{B}}, \mathrm{p}_{\mathrm{A}}, \bar{\theta}\right)-D\left(\mathrm{p}_{\mathrm{B}}, \mathrm{p}_{\mathrm{A}}, \underline{\theta}\right)\right)
$$

\section{$\overline{\text { Insert Figure } 5}$}

This probability is expressed as the product of two terms : the first term is the probability of not learning $\theta$ through observing the aggregate component of demand; the second term is the probability of not learning $\theta$ through observing the shift component of demand. Now, while the first-term can always be reduced through increasing or decreasing the average price level $\frac{\mathrm{p}_{\mathrm{A}}+\mathrm{p}_{\mathrm{B}}}{2}$ (14) , the second term can only be made smaller than 1 if firms price-disperse ! In other words, starting from a symmetric pair of prices $p_{A}=p_{B}=p$ which is not fully informative, firms can always increase the probability of learning by setting $p_{A} \neq p_{B}$. Whenever the value of information $V=\pi_{i}-\pi_{u}$ is strictly positive and the one-shot Nash-equilibrium is not fully informative, price-dispersion around this one-shot NE will generally involve first-order gains in terms of long-run expected profits, which will more than compensate the second-order loss in short-run profits. Proposition 1 will then carry over to this general case.

As it appears, for price dispersion to obtain in equilibrium, two conditions must be satisfied :

a) Information is valuable.

b) Price dispersion increases the amount of information acquired by firms about demand.

Deriving conditions under which the value of information is positive turns out to be difficult and lies beyond the scope of this paper (see section VII for a discussion on this issue). The second condition is purely statistical. In the uniform case analyzed above, firms would either learn the exact value of $\theta$ or nothing. In the general case where noises $\tilde{\varepsilon}_{a}, \tilde{\varepsilon}_{s}$ are distributed according to some (non-uniform) joint density function $\mu\left(\tilde{\varepsilon}_{a}, \tilde{\varepsilon}_{s}\right)$ firms may instead acquire partial information about $\theta$ from observing market data, in which case they both end up with posteriors (q,1-q) that might take any value between 0 and 1. For this general case, we want to compare on informativeness basis the quantity signal generated by a small amount of dispersion to the one generated when there is no price dispersion. In the present framework an appropriate criterion turns out to 


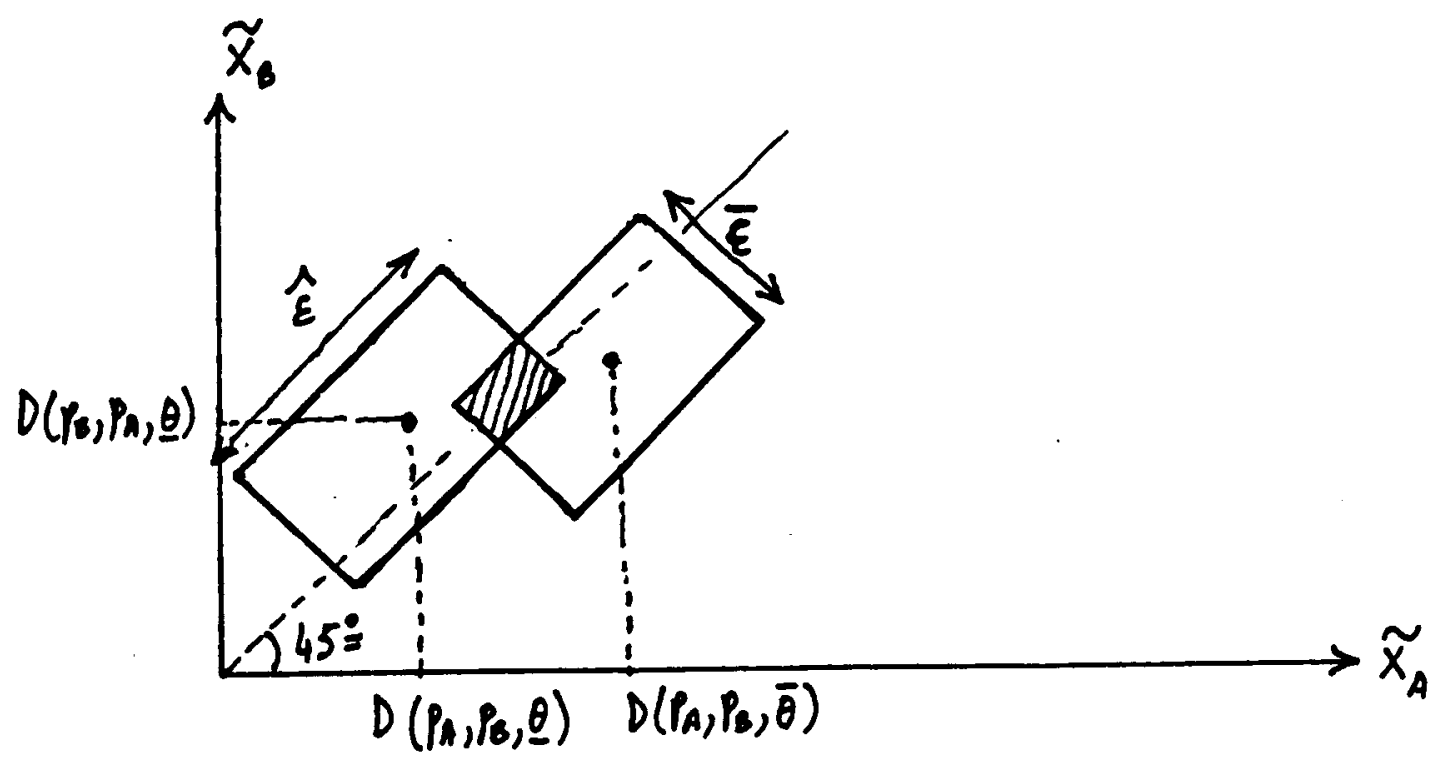

- Figure 5 - 
be the following. Let $s$ be a signal of the parameter $\theta$ leading to some posterior probability $q(s)=\operatorname{prob}(\underline{\theta} / \mathrm{s})$ and let $s^{\prime}$ be another signal leading to posterior $q\left(s^{\prime}\right)=\operatorname{prob}\left(\underline{\theta} / s^{\prime}\right)$; we say that $s^{\prime}$ is more informative than $s^{\prime}$ if for any convex function $\pi$ :

$$
E_{s} \pi(q(s)) \geqslant E_{s}, \pi\left(q\left(s^{\prime}\right)\right) \cdot(15)
$$

This condition ensures that any individual decision maker would prefer signal $\mathbf{s}$ to signal $\mathbf{s}^{\prime}$. We can then establish :

Proposition 3: Assume that $\mu$ is $\mathcal{C}^{1}$, symmetric and quasi-concave in its second argument $\left(\tilde{\epsilon}_{\mathrm{s}}\right)$, then for a fixed level of aggregate demand uncertainty $\left(\Delta D_{A}+\Delta D_{B}\right)$ a small amount of price dispersion is more informative than no dispersion at all.

Proof : see appendix.

This general result is obtained under fairly reasonable assumptions. The symmetry of $\mu\left(\tilde{\epsilon}_{\mathrm{a}}, \tilde{\epsilon}_{\mathrm{s}}\right)$ with respect to $\tilde{\epsilon}_{\mathrm{s}}$ reflects the basic symmetry of the model. Quasi-concavity then amounts to assuming that large shifts in demand from one firm to another are less likely than small shifts.

Remark : With smooth density functions the gain from a small amount of price-dispersion becomes of second order. Therefore price-dispersion will only obtain when firms' discount factor is sufficiently high. Otherwhise firms will not learn the true parameter.

\section{(b) The N-firms case}

As we already pointed out in the introduction, our explanation of price-dispersion as a learning device is complementary to the existing "equilibrium" approach developed in search models and. other models with consumer heterogeneity. An empirical observation that might a priori privilege the search approach is the evidence that price-dispersion also occurs in markets with a large number of sellers (e.g the markets for automobiles). This apparently contradicts what a "n-seller" extension of our model would presumably imply : in our model price-dispersion might indeed rapidly decrease as the number of sellers becomes large, the reason being that the informational effect of a single firm's experimentation would become negligible compared to the cost of such experimentation. Things are not seemingly so clear-cut.

Price dispersion in our model is the only way for oligopolistic firms to acquire more information about their elasticities of substitution. One can think of two polar situations where the number of firms $\mathrm{N}$ tends to infinity, but where the asymptotic results on price-dispersion are 
opposite. In one case, the elasticity of substitution between any two products tends to zero when $\mathbf{N}$ tends to infinity (See Dixit-Stiglitz [1977]). It is then likely that price-dispersion would disappear asymptotically. In the other case each particular firm keeps on having only a small number of close competitors, and moreover the elasticity of substitution between a firm and its closest competitors remains significant as $\mathrm{N}$ becomes large (See Salop [1979]). In that case instead one might expect price-dispersion not to disappear asymptotically. We shall now formally discuss this last conjecture using the N-firm extension of the Hotelling model introduced by Salop [1979].

We consider the case of $N(\geqslant 2)$ oligopolistic firms evenly located on a circle of total length equal to 1 , where consumers are uniformly distributed.

The game lasts for two-periods, according to the same timing as in Section 1 above : before the game starts, all firms ignore the true value of the transportation cost $1 / \theta$, which they may still learn through price-experimenting in period 1 . At each period, each firm $n(1 \leqslant n \leqslant N)$ faces a demand for its product given by :

$$
\tilde{\mathrm{x}}_{\mathrm{n}}=\mathrm{D}_{\mathrm{n}}\left(\mathrm{p}_{1}, \mathrm{p}_{2}, \ldots, \mathrm{p}_{\mathrm{N}} ; \theta\right)+\tilde{\epsilon}_{\mathrm{n}},
$$

where : $D_{n}$ is the deterministic part of $n$ 's demand, which depends on current prices and on the unknown parameter $\theta(16) ;$ and $\tilde{\epsilon}_{n}$ is an idio-syncratic shock which is uniformly distributed on the interval $[-\bar{\epsilon} / 2 \mathrm{~N},+\bar{\epsilon} / 2 \mathrm{~N}]^{(17)}$. Given that the $\mathrm{r} \cdot \mathrm{v} \tilde{\epsilon}_{\mathrm{n}}$ are independantly distributed, we have, by the law of large numbers :

$$
\sum_{n=1}^{N} \tilde{\epsilon}_{n} \rightarrow 0 \text { when } N \rightarrow+\infty
$$

In other words, the situation becomes asymptotically similar to the one described in Section 1 in the sense that the total noise on demand is randomly distributed between the $\mathrm{N}$ oligopolistic firms in such a way that aggregate demand remains deterministic.

We assume that in any period $\tau=1,2$ each firm $n$ observes the whole vector of current prices $\left(p_{1}, \ldots, p_{N}\right)$ plus its own volume of sales $X_{n}$. Under such informational assumption we characterize (see Appendix $B$ ), for each $N$, the second-period equilibrium payoffs as a function of first-period prices and of the observation by each firm of its first-period sales $\tilde{x}_{n}$. The next step is then to derive the first-period price equilibrium.

In Appendix $\mathrm{B}$ we establish the following result : 


\section{Proposition 4 :}

For all $N \geqslant 2$, the learning game with $N$-firms has a symmetric mixed strategy equilibrium with all first-period prices $p_{n}(1 \leqslant n \leqslant N)$ distributed on an interval

$$
[1 / \mathrm{N}(1 / \mathrm{E}(\theta)-\mathrm{K}(\mathrm{N})), 1 / \mathrm{N}(1 / \mathrm{E}(\theta)+\mathrm{K}(\mathrm{N}))]
$$

where $K(N)>0$.

Furthermore the sequence $K(N)$ remains bounded away from zero when $N \rightarrow+\infty$.

In words, price-dispersion does not vanish relatively to the average price level as $N$ goes to infinity. Obviously, in absolute terms, all equilibrium prices converge to the marginal cost zero when $\mathrm{N} \rightarrow+\infty$, the $\mathrm{N}$-firms Hotelling model being asymptotically competitive. However, if we put this "competition effect" aside, our price-dispersion result established in the previous section is robust to introducing a large number of firms.

The asymptotic result stated in Proposition 3, can be explained by the fact that each firm directly competes only with its two neighbours, so that the informational effect of each firm's experimentation remains relatively non-negligible; however the size of the market served by one firm and its two neighbours decreases at the rate $1 / \mathrm{N}$,

\section{(c) Asymmetric duopoly}

So far we have assumed that demand was symmetric among firms. This allowed us to exhibit price-dispersion as an unambiguous equilibrium phenomenon. The logic of the argument extends to the case of a small asymmetry between firms by continuity of the equilibrium correspondance. Namely, if the intrinsic asymmetry between firms is small, price-experimentation will induce them to price disperse to a larger extent than one would expect from asymmetric firms maximizing short-run profits. The following continuity argument is fairly general and applies to both demand and cost asymmetries. Let us for example consider the same Hotelling duopoly game but allow for different transportation cost for each firm. The unit cost of going to firm $A$ is $\frac{1-\lambda}{\theta}$ while the unit cost of going to firm $B$ is $\frac{1+\lambda}{\theta}$, where $\lambda$ is known. Then we can easily construct the equilibria of the one shot game : when firms have posterior $q$, the equilibrium expected profits are

$$
\begin{array}{ll}
\frac{1}{2 E(\theta / q)}\left[1+\frac{\lambda}{3}\right]^{2} & \text { for firm } A \\
\frac{1}{2 E(\theta / q)}\left[1-\frac{\lambda}{3}\right]^{2} & \text { for firm } B
\end{array}
$$

Let $V=\frac{1}{2}\left\{E\left(\frac{1}{\theta}\right)-\frac{1}{E(\theta)}\right\}$, the value of information in this new game is 


$$
\begin{array}{ll}
V_{A}^{\lambda}=V\left[1+\frac{\lambda}{3}\right]^{2} & \text { for firm } A \\
V_{B}^{\lambda}=V\left[1-\frac{\lambda}{3}\right]^{2} \cdot \text { for firm } B
\end{array}
$$

It follows that the expected payoffs in the two period game in terms of first period prices writes as :

$$
\begin{aligned}
\pi_{A}^{\lambda}\left[p_{A}, p_{B}\right]=p_{A}\left[\frac{1+\lambda}{2}+E(\theta) \frac{p_{A}-p_{B}}{2}\right] & +\delta V\left(1+\frac{\lambda}{3}\right)^{2} \min \left\{1, \frac{\Delta \theta\left|p_{A}-p_{B}\right|}{2 \bar{\epsilon}}\right\} \\
& +\delta \pi_{u}\left(1+\frac{\lambda}{3}\right)^{2} \\
\pi_{B}^{\lambda}\left[p_{A}, p_{B}\right]=p_{B}\left[\frac{1-\lambda}{2}+E(\theta) \frac{p_{A}-p_{B}}{2}\right] & +\delta V\left(1-\frac{\lambda}{3}\right)^{2} \min \left\{1, \frac{\Delta \theta\left|p_{A}-p_{B}\right|}{2 \bar{\epsilon}}\right\} \\
& +\delta \pi_{u}\left(1-\frac{\lambda}{3}\right)^{2}
\end{aligned}
$$

We can now consider the game as a one shot game with complete information and payoffs $\pi_{A}^{\lambda}, \pi_{B}^{\lambda}$. But $\pi_{A}^{\lambda}$ and $\pi_{B}^{\lambda}$ are uniformly continuous with $\lambda$. It follows that the equilibrium correspondance is upper-semi-continuous with $\lambda$ at $\lambda=0$. Therefore for $\lambda$ small enough, any equilibrium must be close to an equilibrium of $\lambda=0$. It must then exhibit a finite (zero-order) degree of price dispersion, while the one-shot (myopic) equilibrium exhibits only a first order degree of price dispersion.

\section{The Dynamics of price-dispersion}

In this section we analyze the dynamic evolution of price-dispersion in the context of a $T$-period extension ( $T \geqslant 2$ ) of the Hotelling game described in Section 1. We concentrate our attention on the unique equilibrium path, where, at any date $\tau \in\{1, \ldots, T-1\}$, the duopolists play the (unique) symmetric Nash Equilibrium in the subgame with learning starting at $\tau^{(18)}$. The existence and uniqueness of such equilibrium is guaranted by the following Proposition, which extends the above Proposition 2 to the T-period case :

\section{Proposition 5 :}

For any $\tau<T$, let $t=T-\tau$ and $G_{t}$ denote the $t+1$-period subgame with learning, starting at date $\tau$. Then, $G_{t}$ has a unique symmetric Nash ${ }^{(19)}$ equilibrium, but in mixed strategies, with both $\mathrm{p}_{\mathrm{A}}^{\tau}$ and $\mathrm{p}_{\mathrm{B}}^{\tau}$ (prices played at date $T$ by $A$ and $B$ ) distributed on an interval centered at $1 / E(\theta)$. The diameter of this interval is an increasing function of the value of information at date $\tau+1$.

Proof : see appendix.

In particular, as in the two-period case, the average degree of 
price-dispersion $d_{\tau}$, measured at each date $\tau<T$ by the expected equilibrium value of $\left|p_{A}^{\tau}-p_{B}^{\tau}\right|$, will be proportionnal to the value of information at date $\tau$; since we shall reason by backward induction starting at date $T$, we denote the value of information at date $\tau$ by $V_{t}$, where $t=T-T$ is the remaining number of periods to be played. More precisely :

$$
v_{t}=\pi_{1}^{t}-\pi_{u}^{t}
$$

where :

(a) $\pi_{u}^{t}$ is the expected discounted value of each firm's profits when $t+1$ periods remain to be played and firms are uninformed about $\theta$ at the beginning of period $\tau=T-t$. Equivalently, $\pi_{u}^{t}$ is the average equilibrium payoff for each firm in the subgame $G_{t}$.

(b) $\pi_{i}^{t}$ is the expected discounted value of each firm's profits when $t+1$ periods remain to be played and $\theta$ is to be learned by firms at the beginning of date $\tau$. We simply have :

$$
\pi_{i}^{t}=\frac{1}{2} E(1 / \theta) \cdot\left(1+\delta+\cdots+\delta^{t}\right)
$$

In particular we know from Section 1 that :

$\pi_{u}^{0}=\frac{1}{2 E(\theta)}$ and $\pi_{i}^{0}=\frac{1}{2} E(1 / \theta)$ with a corresponding value of information

$$
V_{0}=\frac{1}{2}(E(1 / \theta)-1 / E(\theta))
$$

It follows from the above Proposition 4 that the dynamic evolution of price-dispersion will primarily depend on the evolution of $V_{t}$ which in turn is governed by the following lemma :

Lemma 1 : $\forall t \in\{1, \ldots, T\}$, we have :

(*) $V_{t}=V_{0}+f\left(V_{t-1}\right)$

where the function $f$ satisfies the following properties :

(a) $f(V) \geqslant 0$ for all $V \geqslant 0$

(b) $f$ is concave in $V$

(c) $f$ is increasing in $V$

(d) $f(V) / V$ tends to 0 when $V$ tends to $+\infty$. (Figure 6 ).

Proof : see appendix.

$$
\overline{\text { Insert Figure } 6}
$$

We can now characterize the evolution of price-dispersion over time : 


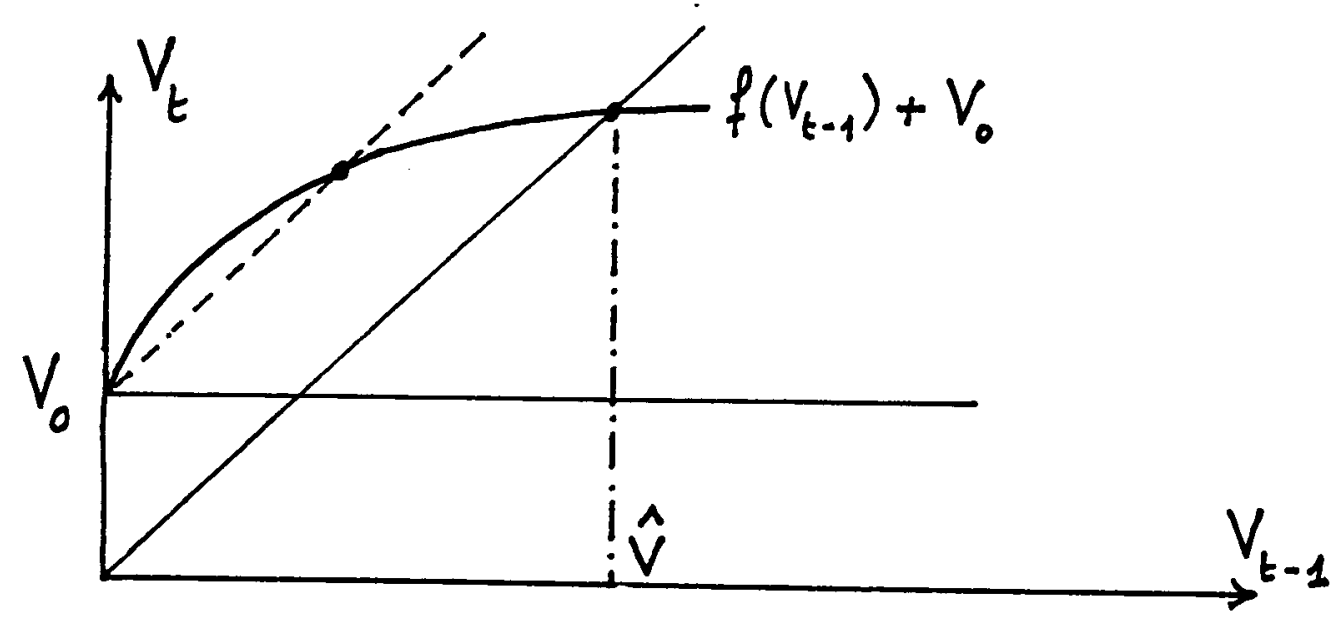

- Figure 6- 
Proposition 6 :

The sequence. $V_{t}$ is increasing in $t$, i.e the average degree of price-dispersion $d_{\tau}$ decreases over time $\tau$. In the last period, $d_{T}=0$.

In other words, both firms start experimenting right away at date $\tau=0$, and then, progressively reduce the amount of experimentation (measured by $\mathrm{d}_{\tau}$ ) as the number of remaining periods over which information about $\theta$ can be profitably used, decreases. Obviously, as soon as firms happen to learn the exact value of $\theta$ they stop experimenting and play the symmetric "informed" Nash equilibrium $p_{A}=p_{B}=1 / \theta$. The probability of firms still being uninformed about $\theta$ decreases with $\tau$, i.e with the number of previous experiments. This, together with Proposition 4, implies that the expected amount of price-dispersion will decrease over time [until it becomes zero in the last period $\tau=T$ where both firms play the myopic equilibrium $p_{A}=p_{B}=1 / E(\theta)$ if they are still uninformed about $\left.\theta\right]$. The same monotonic evolution of price-dispersion will obtain asymptotically when $\mathrm{T} \rightarrow+\infty$ (see our remark below).

This dynamics of price-dispersion reflects the fact, already mentionned in Section 2, that price-experimentation is a disequilibrium phenomenon which tends to vanish over time as firms become better informed about the relevant parameters of demand (or costs). According to our approach, price-dispersion cannot be a persistent phenomenon unless the economic environment (technologies, tastes) incessantly evolves.

\section{Proof of Proposition 6 :}

From Lemma $1(\mathrm{a})$, we have : $f\left(V_{0}\right)>0$.

Therefore: $\mathrm{V}_{1}=\mathrm{V}_{0}+\mathrm{f}\left(\mathrm{V}_{0}\right)>\mathrm{V}_{0}$.

Now, assume that for some $t$, we have : $V_{t-1}>V_{t-2}$.

Then, from $\left({ }^{*}\right)$ and (c) in Lemma 1 :

$$
v_{t}=v_{0}+f\left(V_{t-1}\right)>v_{0}+f\left(v_{t-2}\right)=v_{t-1}
$$

This establishes Proposition 6 by induction.

Remark : Note that (b) and (d) in Lemma 1 imply that the whole sequence $V_{t}$ is bounded above by the stationnary point :

$$
\hat{V}=V_{0}+\mathbf{f}(\hat{V}) \cdot(\text { See Figure } 2) \text {. }
$$

This implies that when $T \rightarrow+\infty$, the value of information $V_{\tau}$ at a given date $\tau$ converges to $\hat{V}$, and similarly the degree of price-dispersion $\mathrm{d}_{\tau}$ converges to some $\hat{\mathrm{d}}$. The dynamic evolution of price-dispersion is then still well defined ; the expected amount of price-dispersion decreases to zero as $\tau$ goes to infinity, but price-dispersion remain constant as long as firms are uninformed. 


\section{$\mathrm{V}$ : Coordination and the advantage of a myopic behavior}

Information in this model is clearly a public good. As for any public good, firms may have the incentive to free-ride on its production. (20) To illustrate this effect we will now briefly discuss the possibility for one firm to behave myopically.

Contrary to the monopoly case, the myopic duopoly firm turns out to do better than a bayesian firm in terms of its expected equilibrium payoff. Indeed being myopic amounts to a precommitment not to experiment, which in turn induces the other firm to bear all experimentation costs.

More surprisingly, the bayesian firm does not loose from being free-rided. The point is that two bayesian firms face a coordination problem as to the optimal choice of their first-period prices. (21) Namely, each firm seeks to move its price away firm its competitor's price, knowing that the competitor follows a similar strategy. Now this coordination problem will be overcome if only one firm experiments at a time. This in turn will benefit the entire industry.

In our framework the coordination improvement brought about by the myopic firm will compensate the bayesian firm for its increased experimentation cost.

Formally, in the context of the two-period Hotelling model introduced in section II, we allow firm A to behave myopically. We shall denote by $\pi(m, b)$ the equilibrium payoff of firm $A$ when it behaves myopically and $B$ behaves non-myopically, and by $\pi(b, m)$ the equilibrium payoff of firm B. We also denote by $\pi(b, b)$ the equilibrium payof $f$ of each firm when both of them are non-myopic.

For simplicity we shall restrict our analysis to the case where :

$$
\mathrm{V}_{0}<\frac{2 \mathrm{E}(\theta)}{\delta \Psi}
$$

where $V_{0}$ is the value of information which we shall again assume to be positive, and $\Psi=\frac{\Delta \theta}{\bar{\epsilon}}$ measures the degree of demand uncertainty faced by both firms.

In appendix $A$, we show that whenever the above inequality (1) holds, the unique symmetric equilibrium of the duopoly game where both firms experiment, involves first-period prices $p_{A}^{1}$ and $p_{B}^{1}$ being both uniformly distributed on the interval :

$$
\left[1 / E(\theta)\left(1-\frac{\delta \Psi V_{0}}{2}\right), 1 / E(\theta)\left(1+\frac{\delta \Psi V_{0}}{2}\right)\right]
$$


(Second period equilibrium prices are both either equal to $1 / \theta$ if firms have learned $\theta$ in period 1 , or to $1 / E(\theta)$ if they haven't.)

The corresponding expected payoff for each firm is then given by :

$$
\text { (2) } \pi(b, b)=(1+\delta) \cdot \frac{1}{2 \mathrm{E}(\theta)}+\frac{\delta^{2} \Psi^{2} \mathrm{~V}_{0}^{2}}{8 \mathrm{E}(\theta)}
$$

Now suppose that firm A behaves myopically.

Figure 7 depicts the reaction functions $R_{A}^{m}\left(p_{B}\right)$ and $R_{B}^{b}\left(p_{A}\right)$ obtained in that case :

$$
\overline{\text { Insert Figure } 7}
$$

The unique Nash equilibrium of the game defined by $R_{A}^{m}$ and $R_{B}^{b}$ involves first-period prices $p_{A}$ and $p_{B}$ given by :

and

$$
p_{A}=\frac{1}{E(\theta)} \text { (one-shot Nash equilibrium level) }
$$

$$
\mathrm{p}_{\mathrm{B}}= \begin{cases}1 / \mathrm{E}(\theta)\left(1+\frac{\delta \Psi \mathrm{V}_{0}}{2}\right) & \text { with probability } 1 / 2 \\ 1 / \mathrm{E}(\theta)\left(1-\frac{\delta \Psi \mathrm{V}_{0}}{2}\right) & \text { with probability } 1 / 2\end{cases}
$$

The myopic firm A's equilibrium payoff is then equal to :

i.e : (4)

$$
\pi(m, b)=(1+\delta) \cdot \frac{1}{2 E(\theta)}+\frac{\delta \Psi \mathrm{v}_{0}}{2} E\left(\left|p_{B}-\frac{1}{E(\theta)}\right|\right)
$$

$$
\pi(m, b)=(1+\delta) \cdot \frac{1}{2 E(\theta)}+\frac{\delta^{2} \Psi^{2} V_{0}^{2}}{4 E(\theta)}
$$

We immediately see (comparing (2) and (4)) that : $\pi(m, b)>\pi(b, b)$. In words, given that its competitor is already committed to a non-myopic behavior, it is strictly profitable for firm A to behave as a myopic firm. The reason is that by letting firm $B$ experiment alone, firm A saves on experimentation costs. All experimentation costs are incurred by firm $B$ whose payof $\pi(b, m)$ is equal to :

$$
\begin{aligned}
\pi(b, m) & =\pi(m, b)-\frac{E(\theta)}{2} \operatorname{var} p_{B} \\
& =(1+\delta) \frac{1}{2 E(\theta)}+\frac{\delta^{2} \Psi^{2} V_{0}^{2}}{4 E(\theta)}-\frac{\delta \Psi^{2} V_{0}^{2}}{8 E(\theta)}=(1+\delta) \frac{1}{2 E(\theta)}+\frac{\delta^{2} \Psi^{2} V_{0}^{2}}{8}
\end{aligned}
$$




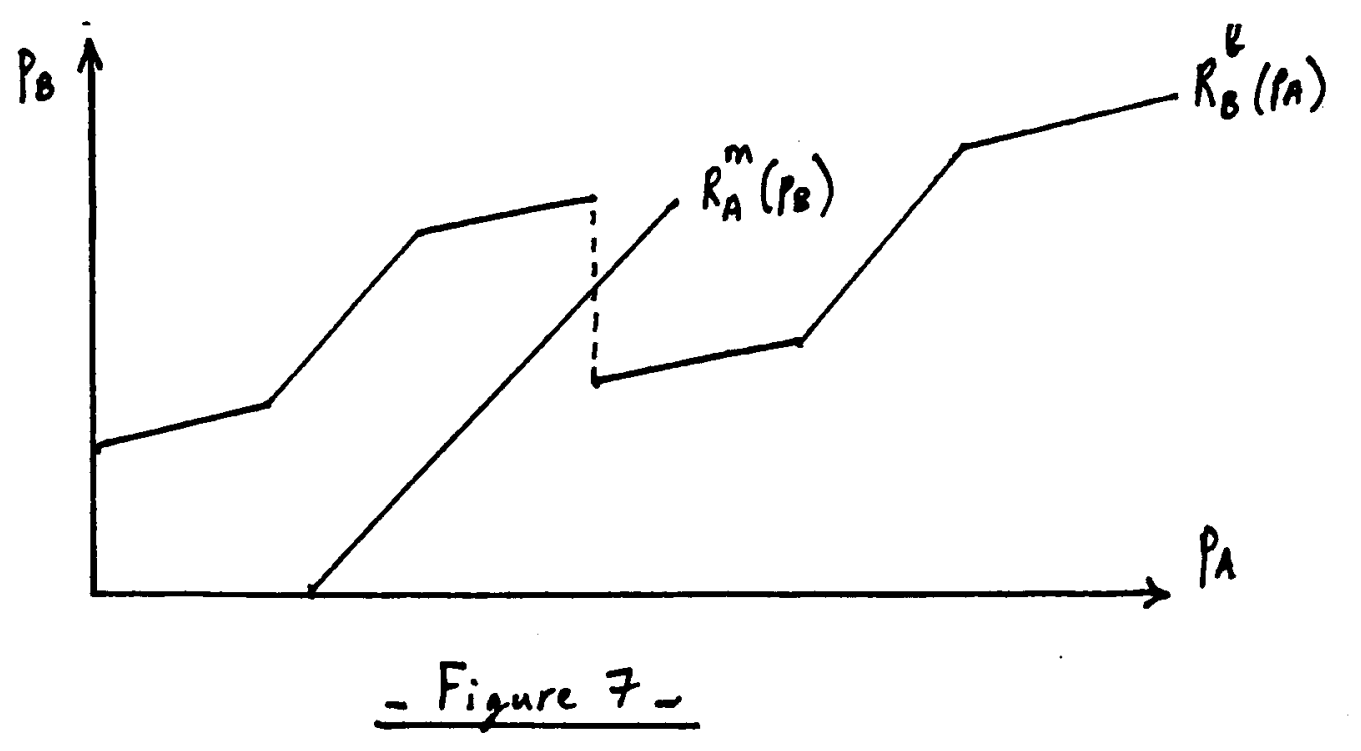


We therefore obtain : $\pi(b, m)=\pi(b, b)$ ! Firm B does not loose when firm A acts myopically. (22) The reason is that although firm B's experimentation cost increases when firm $A$ is myopic, this extra cost is compensated by an increase in firm B's expected informational gain : this gain, proportionnal to the average degree of price-dispersion, is indeed reduced when both firms experiment simultaneously, due to the lack of coordination between their first-period mixed pricing strategies (23). Such coordination problem is automatically overcome if only one firm experiments.

\section{Welfare analysis}

In this section we analyse the welfare implications of duopolists experimenting through prices. As a benchmark we consider the case where the transportation cost $(1 / \theta)$ is publicly announced by a social planner at date 1 . We then compare the total aggregate welfare, the total expected value of profits, and the total consumers'welfare obtained in that case with the corresponding values in the context of our basic two-period model where firms experiment in order to acquire information about $\theta$.

So, let us first assume that the true value $\theta$ is publicly announced at the beginning of the game. The unique PBE is then for both firms to set $p=1 / \theta$ in both periods 1 and 2 . The expected aggregate profits, evaluated at date 0 before the announcement of $\theta$ by the social planner, are given by :

$$
\text { (1) } \Pi_{i}=2 \pi_{i}=(1+\delta) E(1 / \theta)^{(24)}
$$

The aggregate consumers' welfare is then obtained by substracting to the total discounted reservation value $R(1+\delta)\left(=\int_{0}^{1} R(1+\delta) d x\right)$, first the expected aggregate transfer from consumers to firms (i.e $\left.(1+\delta) E(1 / \theta)=\Pi_{1}\right)$ and second the expected discounted sum of transportation costs incurred by all consumers : when $p_{A}=p_{B}=1 / \theta$, all consumers $x \in[0,1 / 2)$ purchase from firm $A$ and the remaining consumers purchase from firm $B$; by symmetry, the total transportation cost per period is equal to : $2 \cdot \int_{0}^{1 / 2} \frac{1}{\theta} \cdot \mathrm{x} d \mathrm{~d}=\frac{1}{4 \theta}$. Hence the expected discounted sum of transportation costs over the two periods is given by :

$$
E_{i}(T)=\frac{1}{4}(1+\delta) \cdot E(1 / \theta)
$$

Overall, the expected consumers' welfare when the true value of $\theta$ is to be publicly announced at date 1 is given by :

$$
w_{i}=R(1+\delta)-\Pi_{1}-\frac{1}{4}(1+\delta) E(1 / \theta)
$$


We now come back to our basic model (introduced in Section 1), where for simplicity we shall assume that :

$$
V_{0}<\frac{2 \cdot E(\theta)}{\delta_{0} \Psi}
$$

where $V_{0}$ is the value of information and $\Psi=\frac{\Delta \theta}{\bar{\epsilon}}$.

We know from the previous section (see Appendix for the formal proof) that whenever (4) is satisfied, the unique symmetric equilibrium of the game $G$ involves first-period prices $p_{A}^{1}$ and $p_{B}^{1}$ being both uniformly distributed on the same interval $\left[1 / \mathrm{E}(\theta)\left(1-\frac{\delta \Psi \mathrm{V}_{0}}{2}\right), 1 / \mathrm{E}(\theta)\left(1+\frac{\delta \Psi \mathrm{V}_{0}}{2}\right)\right]$. The corresponding aggregate profits in the duopolistic industry are then expressed by :

$$
\Pi_{u}=2 \pi_{u}=(1+\delta) \frac{1}{E(\theta)}-\frac{\delta^{2} \Psi^{2} V_{0}^{2}}{12 E(\theta)}+\frac{\delta^{2} \Psi^{2} V_{0}^{2}}{3 E(\theta)}
$$

The first term corresponds to the aggregate profits that would be realized by the industry if both firms were myopic. These profits are obviously made at the expense of consumers. The second term represents the total experimentation cost incurred by both firms. The third term is the total expected gain from experimentation. These last two terms correspond respectively to a positive and a negative transfer to consumers : on the one hand, consumers benefit from price-experimentation since with positive probability they face a first period price below the one-shot Nash-equilibrium $\frac{1}{\mathrm{E}(\theta)}$; on the other hand, price-experimentation increases the probability of firms becoming informed about $\theta$ which in turn increases the expected consumer price in period 2.

We can now express the aggregate consumers' welfare when firms need to price-experiment in order to learn $\theta$; we have :

$$
w_{u}=R(1+\delta)-\Pi_{u}-E_{u}(T)
$$

where $E_{u}(T)$ is the expected discounted sum of transportation costs incurred by all consumers over the two periods of the game. Using the assumption that consumers know the true value of $\theta$ in period 1, we have :

$$
E_{u}(T)=E_{p_{A}^{1}, p_{B}^{1}, \theta}\left(T\left(p_{A}^{1}, p_{B}^{1}, \theta\right)\right)+\delta E_{\theta}\left(T\left(p_{A}^{2}, p_{B}^{2}, \theta\right)\right)
$$

where : 


$$
\begin{aligned}
\mathrm{T}\left(\mathrm{p}_{\mathrm{A}}, \mathrm{p}_{\mathrm{B}}, \theta\right) & =\int_{0}^{1 / 2+\frac{\mathrm{p}_{B}-\mathrm{p}_{\mathrm{A}}}{2} \theta} \frac{\mathrm{x}}{\theta} \cdot \mathrm{dx}+\int_{1 / 2+\frac{\mathrm{p}_{\mathrm{B}}-\mathrm{p}_{\mathrm{A}}}{2} \theta}^{1} \frac{(1-\mathrm{x})}{\theta} \cdot \mathrm{dx} \\
& =\frac{1}{4 \theta}+\frac{1}{4}\left(\mathrm{p}_{\mathrm{B}}-\mathrm{p}_{\mathrm{A}}\right)^{2} \theta
\end{aligned}
$$

Using the fact that in equilibrium $p_{A}^{2} \equiv p_{B}^{2}$ and that $p_{A}^{1}, p_{B}^{1}$ are both uniformly distributed on the interval

$$
\left[1 / \mathrm{E}(\theta)\left(1-\frac{\delta \Psi \mathrm{V}_{0}}{2}\right), 1 / \mathrm{E}(\theta)\left(1+\frac{\delta \Psi \mathrm{V}_{0}}{2}\right)\right] \text {, we obtain : }
$$

$$
E_{u}(T)=\frac{1}{4}(1+\delta) E(1 / \theta)+\frac{\delta^{2} \Psi^{2} V_{0}^{2}}{24 E(\theta)}
$$

Comparing with (2), we see that price-experimentation induces an additional welfare loss (equal to $\left.\frac{\delta^{2} \Psi^{2} V_{0}^{2}}{24 \mathrm{E}(\theta)}\right)$ for consumers who bear higher transportation costs on average.

We can now compare between the aggregate consumers' welfare, respectively when $\theta$ is to be publicly announced by the social planner in period 1 and when firms have to experiment :

$$
\begin{aligned}
w_{u}-W_{i} & =\left(\Pi_{i}-\Pi_{u}\right)-\frac{\delta \Psi^{2} V_{0}^{2}}{24 E(\theta)} \\
& =\left[(1+\delta) V_{0}-\frac{\delta^{2} \Psi^{2} V_{0}^{2}}{8 E(\theta)}\right]-\frac{\delta \Psi^{2} V_{0}^{2}}{24 E(\theta)}
\end{aligned}
$$

This difference is always positive when condition (4) holds.

The first term (in brackets) corresponds to the positive "price-effect" of firms not being publicly informed in period 1 : consumers will then pay lower prices on average. The second term corresponds to the negative "transportation cost effect" : due to firms'price-experimentation, consumers will on average incur higher transportation costs. Overall, the first effect will dominate, i.e the consumers will gain from firms not being publicly informed about $\theta$ at date 1 . At the opposite, firms will 
benefit from being initially informed about $\theta\left(\Pi_{1}>\Pi_{u}\right)$ : they will then charge higher prices on average and also save on experimentation costs.

Finally, a public announcement of $\theta$ in period 1 will increase total welfare $(W+\Pi)$ by the amount $\frac{\delta^{2} \Psi^{2} V_{0}^{2}}{24 E(\theta)}$ which is nothing but the additional transportation cost consumers would incur if firms had to experiment. Note that this gain in total welfare would disappear if firms were myopic : in that case, a public announcement of $\theta$ would simply amount to a positive transfer from consumers to firms, leaving the sum $W+\Pi$ unchanged.

\section{Concluding comments}

\section{The adverse effects of competition on the incentive to learn}

Our analysis so far relied on the value of information being positive. However, the strategic interaction (i.e. price competition) between the duopoly firms raises also the possibility that more information about demand be detrimental to both firms. Such possibility did not exist in the previous sections where, due to a high consumers' reservation value $R$, the average degree of market competition was not affected by firms' information acquisition. (25-26)

Now, we can easily construct an example where competition becomes tougher (on average) as a result of the transportation cost $1 / \theta$ being learned by firms $A$ and $B$. It suffices to choose the reservation value $R$ in the middle range where firms act as local monopolies if $\theta$ is known to be $\underline{\theta}$ and share the whole market if $\theta$ is known to be $\bar{\theta}$.

$$
\begin{aligned}
& \text { Consider the following example: } \\
& \qquad \mathrm{q}_{0}=\frac{1}{2} ; \underline{\theta}=1 ; \bar{\theta}=3 ; \mathrm{R} \in(3 / 4,1) .
\end{aligned}
$$

If firms are uninformed, the equilibrium price is $\frac{1}{2}$ with equilibrium profits $\pi_{u}^{0}=\frac{1}{4}$. If firms know that $\theta=\bar{\theta}$, then they serve the whole market in equilibrium and obtain profits $\pi_{i}^{0}(\bar{\theta})=\frac{1}{6}$. But if firms know that $\theta=\underline{\theta}$, they act as local monopolists and charge $p_{A}=p_{B}=\frac{R}{2}$ with corresponding profits $\pi_{i}^{0}(\underline{\theta})=\frac{R^{2}}{4}$. The value of information in the last period of the game is then negative :

$$
V_{0}=E \pi_{i}^{0}(\theta)-\pi_{u}^{0}=\frac{R^{2}}{8}-\frac{1}{6}<0
$$

One implication of the value of information $v_{0}$ being negative is the multiplicity of symmetric equilibria, which in turn guarantees the existence of collusive symmetric PBE $\dot{\alpha} l a$ Benoit-Krishna. Such equilibria may be criticized on the basis of renegotiation-proofness arguments. In appendix $\mathrm{D}$, we concentrate on a particular type of renegotiation-proof 
equilibrium : namely, the Pareto-dominant Markov Perfect Bayesian Equilibrium (MPBE) ${ }^{(27)}$, where pricing strategies at date $T$ only depend on the information available at that date, with the self-enforcing threat for a deviating firm to learn the detrimental information $\theta$.

It is shown in appendix $D$ that in a T-period game the Pareto-dominant MPBE is symmetric with both firm setting a same price $p^{\top}$ at each date $\tau$. Moreover the equilibrium sequence of prices verifies $\mathrm{p}^{\tau}>\mathrm{p}^{\tau+1}>\ldots>\mathrm{p}^{T}=\frac{1}{\mathrm{E}(\theta)}$. Intuitively, the more periods remain to be played, the more costly it becomes for each firm to deviate from the diagonal $p_{A}=p_{B}$ and thereby reveal the detrimental information about $\theta$; therefore the easier it becomes for both firms to "collude" on higher prices. As it appears, when the value of information is negative, the possibility of experimentation leads to an equilibrium outcome similar to collusion although not based on any threat of retaliation from one player to another.

\section{On the dynamic evolution of the value of information}

Our dynamic results on the value of information (which we showed to be monotonically decreasing when $\mathrm{V}_{0}>0$ and monotonically increasing when $\left.V_{0}<0\right)$ relied heavily on having selected one particular type of equilibrium. For example in the T-period game with $V_{0}>0$ (Section IV above) we disregarded the asymmetric equilibria. However such equilibria might be quite useful as potential threats in order to sustain collusive outcomes, in the spirit of Benoit-Krishna (1985) : the idea is to punish any deviating firm in period 1 by playing the worst asymmetric equilibrium for that firm in period 2. [Such threat is credible since the worst asymmetric equilibrium for one firm (say A) is also the best asymmetric equilibrium for the other firm $B]$. To the extent that a collusive strategy $p_{A}=p_{B}=p^{c}$ could be sustained in equilibrium at the early stages of the game, the value of information at date $\tau=1$ might well be negative equal to $\left(\pi_{i}-\pi^{c}\right)$, [where $\pi_{i}$ is the informed equilibrium payoff $E(1 / \theta)(1+\delta+\cdots)$ and $\pi^{c}$ is the collusive payof $f$ ] even though the value of information ends up being positive equal to $\mathrm{V}_{0}>0$ at date $\tau=T-1$. In appendix $\mathrm{D}$ we construct an example of a 3-period Hotelling game where the value of information $V_{2}$ at the beginning of the game is negative even though $V_{1}$ and $V_{0}$ are positive. One might then reproduce the analysis developed above and show the existence of a "collusive-type" equilibrium where the average price level starts decreasing up to $\tau=T-2$ and then increases.

The reverse phenomenon when $\mathrm{V}_{0}<0$ may also occur. 


\section{Value of information and Price discrimination ${ }^{(28)}$}

As we shall now argue, analyzing the value of price-discrimination in oligopoly games is formally equivalent to analyzing the value of information along the lines followed throughout this paper.

Consider first the one-period duopoly game with incomplete information defined by the demand curves : $D_{A}=D\left(p_{A}, p_{B}, \theta\right)$ for firm $A$ $D_{B}=D\left(p_{B}, p_{A}, \theta\right)$ for firm $B$,

where $\theta \in\{\underline{\theta}, \bar{\theta}\}$ and $q=\operatorname{pr}(\underline{\theta})$ is the prior probability distribution on $\theta$.

If firms remain uninformed about $\theta$, they will play the duopoly game with payoff function: $p_{A}\left(q D\left(p_{A}, p_{B}, \underline{\theta}\right)+(1-q) D\left(p_{A}, p_{B}, \bar{\theta}\right)\right)$ for firm $A$, and symmetrically for firm $B$. Let $\pi_{u}$ denote the (unique) equilibrium payof $f$ of that "uninformed" game.

Now suppose that firms receive a signal $s$ of the unknown parameter $\theta$, with $q(s)=$ proba $(\underline{\theta} \mid s)$; we denote by $H(s)$ the c.d.f. of $s$.

Firms will then play the duopoly game $G(s)$ with payoff function :

$$
p_{A}\left(q(s) D\left(p_{A}, p_{B}, \underline{\theta}\right)+(1-q(s)) D\left(p_{A}, p_{B}, \bar{\theta}\right)\right) \text { for firm } A
$$

and symmetrically for firm B. If $\pi(s)$ denotes the equilibrium payoff of that game, the ex-ante value of information $s$ is simply given by :

$$
\int \pi(s) d H(s)-\pi_{u}=V(s)
$$

Consider now the game with complete information where a fraction $q$ of consumers have demand $D\left(p_{A}, p_{B}, \underline{\theta}\right)$ and a fraction $(1-q)$ have demand $D\left(p_{A}, p_{B}, \underline{\theta}\right)$ for firm $A^{\prime} s$ product. (Symmetrically for firm B's product). If firms are not allowed to price-discriminate, their payof functions will look identical to the uninformed case described above. Suppose now that firms are allowed to price-discriminate on the basis of some signal s such that :

- among the set of consumers with signal $s$, a fraction $q(s)$ is of type $\underline{\theta}$.

- $s$ is distributed according the c.d.f. $H(s)$ within the entire population.

The value of price-discrimination will thus be equal to :

$$
\int \pi(s) d H(s)-\pi_{u}=V(s)
$$


More generally, price-discrimination will be profitable precisely in those situations where, having reinterpreted the duopoly model as one with incomplete information about $\theta$, the value of information is positive, so that non-myopic firms would price-experiment in equilibrium.

Now, as the previous comment suggests, evaluating whether the value of information will be positive or negative in a general context turns out to be a difficult task which goes beyond the scope of this paper. 


\section{FOOTNOTES}

(1) M. Rothschild (1973) "Models of market organization with imperfect information : a survey", Journal of Political Economy, 81, pp 1283-1308.

(2) Significant progress has been made toward a "satisfactory" theory of price adjustment by a monopoly, based on price experimentation (See Rothschild (1974), Mc Lennan (1984), Easley-Kiefer (1988) and Aghion, Bolton, Harris, Jullien (1990)).

(3) Another weakness of this approach is that in infinite horizon settings, the set of Nash-equilibria in the appropriately defined super-game is typically very large.

(4) In an analysis of the 1981. Vancouver gasoline market, M. Slade (1986,1989) established that following a major change in US-Canadian gasoline relative price, the market displayed a large degree of price-volatility and price-dispersion for about one year before stabilizing to a situation without dispersion. Our analysis provides a convincing explanation for this phenomenon.

(5) Other explanations of price-dispersion have been developed, which all view price-dispersion as a long-run equilibrium phenomenon. Most of these explanations are based on the existence of search costs. A noticeable difference between the search models and the one developed in this paper is that the former do not exclude the existence of a symmetric equilibrium where all firms set the same price (See Salop-Stiglitz (1977), Burdett and Judd (1983), Butters (1977)...). By contrast, our approach excludes the existence of a symmetric equilibrium and therefore can predict price dispersion without any ambiguity. Furthermore, the alternative theories of price-dispersion rely either on ex-ante asymmetries among consumers (for example, on heterogeneous search costs as in Salop-Stiglitz (1977), on different propensities to search as in Wild and Schwartz (1975), or on an unequal access to price ads as in Butters (1977)) ; or they do rely, as in Reinganum (1979), upon assuming a heterogeneous marginal cost structure across firms. Our approach, instead, does not rely on any asymmetry (ex-ante or ex-post) on the consumers'side or on the firms'side.

(6) This free rider aspect has been emphasized by R. Rob (1988) in a sequential model of entry.

(7) See Aumann and Maschler (1967) and Ponssard (1979) who both emphasize

the possibility of a negative social value of information in games.

(8) We should not a priori exclude the possibility for consumers to 
communicate the true value of $\theta$ to the firms from which they purchase. This, however, cannot be incentive-compatible if the mill-price set by each firm is independant of consumers'announcements, as we assume throughout this paper.

(9) The assumption $\bar{\theta} \leqslant 2 \underline{\theta}$ is made for the purpose of simplification, see footnote (5).

(10) In Section 3 below we shall extend our analysis to the general case where aggregate demand is also random.

(11) In this Hotelling duopoly model where aggregate demand is fixed, it is equivalent to assume that both firms observe both $\tilde{\mathrm{X}}_{\mathrm{A}}$ and $\tilde{\mathrm{X}}_{\mathrm{B}}$. However our main result will be extended to the N-firms case where each oligopolist only observes its own volume of sales $\tilde{\mathrm{X}}_{1}$.

(12) This claim is not straightforward because a firm can ignore the possibility that $\theta=\bar{\theta}$ and try to make profits only when $\theta=\underline{\theta}$ by charging a high price. The best response curve of $A$ is :

$$
\left\{\begin{array}{l}
p_{A}=\frac{1}{2}\left(\frac{1}{E(\theta)}+p_{B}\right) \quad \text { if } \quad p_{B}>\text { inf }\left\{\frac{1}{\sqrt{\underline{\theta} E(\theta)}}, \frac{1}{\underline{\theta}}-\frac{2}{\bar{\theta}}\right\} \\
p_{A}=\frac{1}{2}\left(\frac{1}{\theta}+p_{B}\right) \quad \text { otherwise }
\end{array}\right.
$$

which reduces to $p_{A}=\frac{1}{2}\left(\frac{1}{E(\theta)}+p_{B}\right)$ if $\bar{\theta} \leqslant 2 \underline{\theta}$. If $\frac{\bar{\theta}}{\underline{\theta}}$ is very large, there exist no pure strategy symmetric equilibrium.

We thank one referee for pointing this out.

(13) See below for a generalization to the case where $\left(\tilde{\epsilon}_{a}, \tilde{\epsilon}_{s}\right)$ are distributed according to a joint density function $\mu\left(\tilde{\epsilon}_{a}, \tilde{\epsilon}_{s}\right)$.

(14) In Aghion-Espinoza-Jullien (1988) we show that learning considerations actually tend to move the average price level $\frac{p_{A}+p_{B}}{2}$ in first-period equilibrium away from the one-shot Nash level and in the direction in which the distance between the two aggregate demand functions $D(p, p, \underline{\theta})$ and $D(p, p, \bar{\theta})$ increases.

(15) Assume that for any posterior $q$, the second period game has a unique symmetric equilibrium with equilibrium payof $\pi(q)$ for both firms. Then one can easily show that in order for any information about $\theta$ to have a positive value it is neccessary and sufficient that $\pi$ be convex. Under such 
property, the criterion $\left(^{*}\right)$ garantees that a small amount of price-dispersion increases expected second-period payoffs compared to no price dispersion.

(16) More precisely, $D_{n}\left(p_{1}, \ldots, p_{N}, \theta\right)=\frac{1}{N}+\theta\left(\frac{p_{n-1}+p_{n+1}}{2}-p_{n}\right)$.

(17) Had the size of the noise $\tilde{\epsilon}$ been kept independant of $\mathrm{N}(\mathrm{e} . \mathrm{g}$ equal to $\bar{\epsilon}$ instead of $\bar{\epsilon} / \mathrm{N})$, the deterministic part of each firm's demand would become proportionally negligible as $\mathrm{N} \rightarrow \infty$, i.e the demand faced by each firm would become entirely random asymptotically. Then, not surprisingly, price-dispersion would bring no information as $\mathrm{N} \rightarrow \infty$. However such conclusion seems rather uninteresting and in particular it does not answer the above conjecture.

(18) If duopolists know $\theta$ at the beginning of period $\tau$, they obviously play the unique "informed" equilibrium $\mathrm{p}_{\mathrm{A}}^{\top}=\mathrm{p}_{\mathrm{B}}^{\tau}=1 / \theta$.

(19) This proposition implies that all continuation subgames of $\mathrm{G}_{\mathrm{T}}$ (even those which are off-the-equilibrium-path) have a unique symmetric Nash equilibrium. However, these games also have asymmetric equilibria (in pure strategies), the multiplicity of which raises the issues of coordination or collusion between the two experimenting firms. We refer to the concluding section for a discussion of these issues.

(20) A similar free-rider situation has been analyzed by R. Rob [1988] : he considers a sequential model of entry into a new industry whose total demand is unknown initially. Information about the size of that demand is revealed over time as new firms enter the market. Early entrants exert a positive informational externality on late entrants so that each potential entrant has an incentive to delay entry. This results in a sub-optimal rate of entry.

(21) Indeed, when both firms experiment simultaneously, the unique symmetric Nash equilibrium involves both firms setting first-period prices which are almost equal (and therefore uninformative) with positive probability. The probability of such lack of coordination becomes zero if only one firm experiments. Another aspect of this coordination problem is the existence of three equilibria (including two asymmetric equilibria) when both firms experiment, and only one when one firm experiments. A similar coordination problem has been printed out in a non-bayesian context by Kirman (1986).

(22) One may imagine a preliminary game where firms choose whether to behave myopically or non-myopically. This game would have two asymmetric pure strategy equilibria where one of the firm chooses to behave myopically 
and one mixed strategy equilibrium where each firm chooses with probability $\frac{1}{2}$ to behave myopically.

(23) From $\frac{\delta^{2} \Psi^{2} V_{0}^{2}}{6 E(\theta)}$ when both firms experiment, to $\frac{\delta^{2} \Psi^{2} V_{0}^{2}}{4 E(\theta)}$ when only one firm experiments. The experimentation cost incurred by each firm in the former case is : $\frac{\delta^{2} \Psi^{2} V_{0}^{2}}{24 E(\theta)}$.

(24) There are two firms, each of them with the same expected payof in equilibrium.

(25) More precisely, the aggregate demand remained constant at $\tilde{X}_{A}+\tilde{X}_{B}=1$ and so did the average price level $\frac{\bar{P}_{A}+\bar{P}_{B}}{2} \equiv 1 / E(\theta)$.

(26) The reader is referred to Section VII.2 for an example where the value of information is negative in a three-period version of the Hotelling game, even though the reservation value $R$ is high.

(27) We thank an anonymous referee for pointing out that some theoretical difficulties with the concept of MPBE still remain unsolved. These difficulties appear mainly in situations where agents are indifferent between two continuation equilibria at some point in the course of the game. Such non-generic situations do not occur in our model. On the other hand,our conclusion about the existence of high priced collusive equilibria would only be reinforced if we considered all PBE and then combine the threat of learning $\theta$ with the threat of playing a low payof $f$ uninformative equilibrium. The latter threat relies on the multiplicity of symmetric PBE that arises when the value of information $V^{0}$ is negative.

(28) We thank an anonymous referee for suggesting this comment. 


\section{REFERENCES}

Aghion, P., Bolton, P., Harris, C. and B. Jullien (1990), "Optimal Learning by Experimentation," Mimeo Nuffield College.

Aumann, R. and M. Maschler (1967), "Repeated Games with Incomplete Information : A Survey of Recent Results," Report of the U.S. Arms Control and Disarmament Agency, Washington, DC.

Burdett, K. and . Judd (1983), "Equilibrium Price-Dispersion," Econometrica $51, n^{\circ} 4,955-969$.

Butters G. (1977), "Equilibrium Distributions of Sales and Advertising Prices," Review of Economic Studies, XLIV, 465-491.

Grawford, V.P. and H. Haller (1990), "Learning How to Cooperate : Optimal Play in Repeated Coordination Games", forthcoming, Econometrica.

Cyert, R. and M. DeGroot, "Interim Learning and the Kinked Demand Curve," Journal of Economic Theory. III (1971), 272-287.

Easley, D. and N. Kiefer (1988), "Controlling a Stochastic Process with Unknown Parameters", Econometrica 56, n 5, pp. 1045-1064.

Kirman, A. (1985), "On Mistaken Beliefs and Resultant Equiliria", in : Individual forecasting and aggegrate outcomes, edited by Frydman $\mathrm{R}$. and E. Phelps, pp 147-168. Cambridge University Press.

McLennan, A. (1984), "Price Dispersion and Incomplete Learning in the Long Run," Journal of Economic Dynamics and Control 7, 331-347.

Ponssard, J.P., "The Strategic Role of Information on Demand Function in an Oligopolistic Market," Management Science, XXV (1979), 243-250.

Reinganum, J., "A Simple Model of Equilibrium Price Dispersion," Journal of Political Economy, XXCVII (1979), 851-858.

Riordan, M., "Imperfect Information and Dynamic conjectural Variations," Rand Journal of Economics, XVI (1985), 41-50.

Salop, S. and J. Stiglitz, "Bargains and Ripoffs : A Model of Monopolistically Competitive Price Dispersion," Review of Economic Studies, XXIV (1977), 493-510.

Rothschild, M. (1973), "Models of Market Organization with Imperfect 
Information. A Survey," Journal of Political Economy, 81, 1283-1308.

Rothschild, M. (1974), "A Two-Armed Bandit Theory of Market Pricing", Journal of Economic Theory, 9, 185-202.

Slade, M.E. (1986), "Conjectures, Firm Characteristics, and Market Structure : An Empirical Assessment," International Journal of Industrial Organization, 4, 347-369.

Slade, M.E. (1989), " Learning Through Price Wars : An exercise in Uncovering Supergame Strategies", Mimeo, University of British Columbia.

Wilde, L. and A. Schwartz, "Equilibrium Comparison Shopping," Review of Economic Studies, (1979), 543-553. 
Appendix A (Section II).

\section{A.1 Reaction correspondance of firm A.}

Profits are $\frac{E(\theta)}{2} p_{A}\left(\frac{1}{E(\theta)}+p_{B}-p_{A}\right)+\delta V \min \left\{1, \frac{\psi}{2}\left|p_{B}-p_{A}\right|\right\}+\delta \pi_{u}$ where $\psi=\frac{\Delta \theta}{\varepsilon}$.

$$
\text { Define } \quad \begin{aligned}
\tilde{p}_{A}\left(p_{B}\right)=\frac{1}{2}\left(p_{B}+\frac{1}{E(\theta)}\right) \\
\quad p_{A}^{*}\left(p_{B}\right)=\tilde{p}_{A}\left(p_{B}\right)-\frac{\delta V \psi}{2 E(\theta)} \\
p_{A}^{* *}\left(p_{B}\right)=\tilde{p}_{A}\left(p_{B}\right)+\frac{\delta V \psi}{2 E(\theta)}
\end{aligned}
$$

The best response is :

$\tilde{p}_{A}\left(p_{B}\right)$ if it is fully informative, therefore if $\left|\tilde{p}_{A}-p_{B}\right| \geqslant \frac{2}{\psi}$ or $\left|p_{B}-\frac{1}{E(\theta)}\right| \geqslant \frac{4}{\psi}$.

Otherwhise A plays when $p_{B}>\frac{1}{E(\theta)}$.

$\left\{\begin{array}{l}\mathrm{p}_{\mathrm{A}}^{*} \text { if }\left|\mathrm{p}_{\mathrm{A}}^{*}-\mathrm{p}_{\mathrm{B}}\right|<\frac{2}{\psi} \text { or } \mathrm{p}_{\mathrm{B}} \leqslant \frac{1}{\mathrm{E}(\theta)}-\frac{\delta V \psi}{2 \mathrm{E}(\theta)}+\frac{4}{\psi} \\ \mathrm{p}_{\mathrm{B}}-\frac{2}{\psi} \text { if not. }\end{array}\right.$

and $A$ plays when $p_{B}<\frac{1}{E(\theta)}$

$\mathrm{p}_{\mathrm{A}}^{* *}$ if $\left|\mathrm{p}_{\mathrm{A}}^{* *}-\mathrm{p}_{\mathrm{B}}\right|<\frac{2}{\psi}$ or $\mathrm{p}_{\mathrm{B}} \geqslant \frac{1}{\mathrm{E}(\theta)}+\frac{\delta \mathrm{V} \psi}{2 \mathrm{E}(\theta)}-\frac{4}{\psi}$

$p_{B}+\frac{2}{\psi}$ if not.

At $\mathrm{p}_{\mathrm{B}}=\frac{1}{\mathrm{E}(\theta)} ; \mathrm{A}$ is indifferent between $\mathrm{p}_{\mathrm{A}}^{*}$ and $\mathrm{p}_{\mathrm{A}}^{* *}$ if $\frac{4}{\psi}>\frac{\delta V \psi}{2 \mathrm{E}(\theta)}$ and $\mathrm{p}_{B}+\frac{2}{\psi}, \mathrm{p}_{\mathrm{B}}-\frac{2}{\psi}$ otherwhise.

\section{A.2 Proof of proposition 2}

To simplify notations let us define

$$
\lambda=\frac{\delta V}{E(\theta)}, \tau=\frac{2 \bar{\varepsilon}}{\Delta \theta}, x=p_{A}-\frac{1}{E(\theta)}, y=p_{B}-\frac{1}{E(\theta)} .
$$


With these notations the payoff of firm $A$ is given by :

$\pi_{A}(x, y)=\frac{1}{2 E(\theta)}+\frac{y}{2}+\delta \pi_{u}+E(\theta)\left\{-\frac{x^{2}}{2}+x \frac{y}{2}+\lambda \min \left\{1, \frac{|x-y|}{\tau}\right\}\right\}$

Let us consider a symmetric equilibrium where $\mathrm{x}$ and $\mathrm{y}$ have cumulative F, then :

$E \lambda \min \left\{1, \frac{|x-y|}{\tau}\right\}=\frac{\lambda}{\tau}\left\{\tau+\int_{x-\tau}^{x} F(y) d y-\int_{x}^{x+\tau} F(y) d y\right\}$.

Lemma A.1 : F is continuous.

Proof : Let $\pi(x)=\int \pi_{A}(x, y) d F(y)$. Then a necessary condition for $F$ to be an equilibrium distribution is that for all $x$ in the support of $F$ : $\pi_{-}^{\prime}(x) \geqslant 0 \geqslant \pi_{+}^{\prime}(x)$. This writes as

$\frac{\lambda}{\tau}\left\{2 F_{+}(x)-F_{+}(x-\tau)-F_{+}(x+\tau)\right\} \leqslant x-\frac{E(y)}{2} \leqslant \frac{\lambda}{\tau}\left\{2 F-(x)-F_{-}(x-\tau)-F_{-}(x+\tau)\right\}$. But then $\operatorname{pr}(x)-\operatorname{pr}(x-\tau) \leqslant \operatorname{pr}(x+\tau)-\operatorname{pr}^{2}(x)$,

which is only possible if $\operatorname{pr}(x+\tau)=\operatorname{pr}(x-\tau)=\operatorname{pr}(x)=0$

Q.E.D.

Lemma A.2 : The support of $F$ is an interval $\left[k_{1}, k_{2}\right]$. Moreover if $F$ with support $\left[k_{1}, k_{2}\right]$ is such that $\pi^{\prime}(x)=0$ on the support, $F$ is an equilibrium distribution.

Proof $: \pi^{\prime}(x)=-x+\frac{E(y)}{2}+\frac{\lambda}{T}\{2 F(x)-F(x-\tau)-F(x+\tau)\}$. Consider $x<z$ with $F(x)=F(z)$. If $\pi^{\prime}(x)=0$, then $\pi^{\prime}(z)<0$ since $F(x+\tau) \leqslant F(z+\tau)$ and $F(x-\tau) \leqslant F(z-\tau)$. Similarly if $\pi^{\prime}(z)=0$, then $\pi^{\prime}(x)>0$. This shows first that if $x$ and $z$ are in the support of $F$, no point in between can be outside the support. In addition if for all $x \in \operatorname{Supp} F=\left[k_{1}, k_{2}\right], \pi^{\prime}(x)=0$, then $\pi^{\prime}(z)>0$ for $z<k_{1}$ and $\pi^{\prime}(z)\left\langle 0\right.$ for $z>k_{2}$ which shows that $F$ is an equilibrium.

Lemma A.3 : Let $x_{0} \in\left[k_{1}, k_{1}+\tau\right]$ and $x_{n}=x_{0}+n \tau$. Then if $x_{n-1} \leqslant k_{2}$ :

$$
F\left(x_{n}\right)=(n+1) F\left(x_{0}\right)-\frac{\tau}{\lambda}\left\{\left(x_{0}-\frac{E(y)}{2}\right) \frac{n(n+1)}{2}+\tau \frac{n(n+1)(n-1)}{6}\right\} \text {. }
$$

Proof : this follows by solving the system

$$
\left\{\begin{array}{l}
F\left(x_{1}\right)-F\left(x_{0}\right)=F\left(x_{0}\right)-\frac{\tau}{\lambda} x_{0}-\frac{\tau}{\lambda} \frac{E(y)}{2} \\
\vdots \\
F\left(x_{n}\right)-F\left(x_{n-1}\right)=F\left(x_{n-1}\right)-F\left(x_{n-2}\right)-\frac{\tau}{\lambda} x_{n-1}+\frac{\tau}{\lambda} E(y) / 2
\end{array}\right.
$$

which expresses $\pi^{\prime}\left(x_{\ell}\right)=0$ for $\ell=0 \ldots n-1$.

Q.E.D. 
Let $(\alpha, N)$ be defined by $\frac{(N+1)(N+2)}{12}\left(N+\frac{3 \alpha}{\tau}\right) \tau=\frac{\lambda}{\tau}, 0 \leqslant \alpha<\tau$.

Proposition : There is a unique symmetric equilibrium given by :

$\mathrm{k}_{2}=-\mathrm{k}_{1}=\mathrm{K}=\frac{\mathrm{N}}{2} \mathrm{~T}+\frac{\alpha}{2}$.

if $x \in] \mathrm{k}_{1}+\mathrm{n} \tau, \mathrm{k}_{1}+\mathrm{n} \tau+\alpha[$ where $0 \leqslant \mathrm{n} \leqslant \mathrm{N}$, then

if $x \in] k_{1}+n \tau+\alpha, k_{1}+(n+1) \underset{T}{2 \lambda}$ where $0 \leqslant n<N$, then

$$
\begin{aligned}
& F^{\prime}(x)=\frac{T}{2 \lambda}(n+1)(N+1 \\
& +(n+1) T[\text { where } \\
& (x)=\frac{T}{2 \lambda}(n+1)(N-n)
\end{aligned}
$$

Proof : Let $k_{2}=k_{1}+N \tau+\alpha$ for some $N \geqslant 0,0 \leqslant \alpha<\tau$. Let $x \in\left[k_{1}, k_{1}+\alpha\right]$ and apply lemma 3 to $n=N+1$ using $F(z)=1$ if $z \geqslant k_{2}$, this leads to

$F(x)=\frac{1}{N+2}+\frac{\tau}{\lambda}\left\{\frac{N+1}{2}\left(x-\frac{E(y)}{2}\right)+\frac{T}{6} N(N+1)\right\}$.

Let $x \in\left[k_{1}+\alpha, k_{1}+\tau\right]$ and apply lemma 3 to $n=N$ :

$$
F(x)=\frac{1}{N+1}+\frac{\tau}{\lambda}\left\{\frac{N}{2}\left(x-\frac{E(y)}{2}\right)+\frac{\tau}{6}(N-1) N\right\}
$$

As $F\left(k_{1}\right)=0$ we have $k_{1}=\frac{E(y)}{2}-\frac{2 \lambda}{\tau} \frac{1}{(N+1)(N+2)}-\tau \frac{N}{3}$.

Equalizing the two formulas for $\mathrm{x}=\mathrm{k}_{1}+\alpha$ leads to

$\alpha=\frac{4 \lambda}{\tau} \frac{1}{(\mathrm{~N}+1)(\mathrm{N}+2)}-\tau \frac{\mathrm{N}}{3}$ which is equivalent to

Given the formula of $\alpha, \frac{12}{T \text { we obtain }}\left(N+\frac{3 \alpha}{\tau}\right)=\frac{\lambda}{\tau}$.

(A.1) $\left\{\begin{array}{l}k_{1}=\frac{E(y)}{2}-\frac{N \tau}{2}-\frac{\alpha}{2} \\ k_{2}=\frac{E(y)}{2}+\frac{N \tau}{2}+\frac{\alpha}{2}\end{array}\right.$

Let us now compute the densities.

For $x \in] k_{1}, k_{1}+\alpha[$ the density is

$$
F^{\prime}(x)=\frac{T}{\lambda} \frac{N+1}{2}
$$

For $x \in] k_{1}+\alpha, k_{1}+\tau[$, the density is

$$
F^{\prime}(x)=\frac{T}{\lambda} \frac{N}{2}
$$

From lemma $3: F^{\prime}(x+n \tau)=(n+1) F^{\prime}(x)-\frac{\tau}{\lambda} \frac{n(n+1)}{2}$.

Applying these formulas to $x \in] \mathrm{k}_{1}, \mathrm{k}_{1}+\alpha[$ and $\mathrm{x} \epsilon] \mathrm{k}_{1}+\alpha, \mathrm{k}_{1}+\tau[$, gives the densities in the proposition.

In thus just remains to compute $E(y)$. Notice that the distribution is such that

$$
F^{\prime}\left(k_{1}+x\right)=F^{\prime}\left(k_{2}-x\right)
$$


It follows immediatly that

$$
E(y)=\frac{k_{1}+k_{2}}{2}=\frac{E(y)}{2}
$$

This is only possible if $\mathrm{E}(\mathrm{y})=0$ which complete the proof.

Q.E.D.

Obviously $\mathrm{K}$ is increasing with $\lambda=\frac{\delta V}{\mathrm{E}(\theta)}$. Now $\mathrm{K}$ is continuous with $\tau=\frac{2 \bar{\varepsilon}}{\Delta \theta}$.

Moreover $K=\frac{N \tau}{3}+\frac{2 \lambda}{\tau(N+1)(N+2)}$.

Consider $\tau$ such that $\frac{N(N+1)(N+2)}{12}<\frac{\lambda}{\tau^{2}}<\frac{(N+1)(N+2)(N+3)}{12}$, then

$$
\frac{\mathrm{dK}}{\mathrm{d} \tau}=\frac{2}{(\mathrm{~N}+1)(\mathrm{N}+2)}\left[\frac{\mathrm{N}(\mathrm{N}+1)(\mathrm{N}+2)}{6}-\frac{\lambda}{\tau^{2}}\right]
$$

If $N \geqslant 3$, then $\frac{(N+1)(N+2)(N+3)}{12} \leqslant \frac{N(N+1)(N+2)}{6}$ and $\frac{d K}{d \tau}>0$ this corresponds to the case $\tau$ shmall.

If $\mathrm{N}=0, \frac{\mathrm{dK}}{\mathrm{d} \tau}$ is negative.

For the case $\frac{1}{2}>\frac{\lambda}{\tau^{2}}$, then $N=0$ so that the equilibrium is given by

$$
\mathrm{p}_{\mathrm{A}}, \mathrm{p}_{\mathrm{B}} \text { uniform on }\left[\frac{1}{\mathrm{E}(\theta)}-\frac{\delta \mathrm{V}}{2 \mathrm{E}(\theta)} \frac{\Delta \theta}{\bar{\varepsilon}}, \frac{1}{\mathrm{E}(\theta)}+\frac{\delta \mathrm{V}}{2 \mathrm{E}(\theta)} \frac{\Delta \theta}{\bar{\varepsilon}}\right]
$$

In the example of section $\mathrm{II}$

$$
\tau=\frac{3}{4}, \lambda=\frac{\delta}{16}, \quad \frac{\delta \mathrm{V} \Delta \theta}{2 \mathrm{E}(\theta) \bar{\varepsilon}}=\frac{\delta}{12}
$$

\section{A. 3 Asymmetric pure stragegy equilibria}

As long as $\frac{\delta V}{E(\theta)}<3\left(\frac{\bar{\varepsilon}}{\Delta \theta}\right)^{2}$ the reaction curves cross at two points

$$
\begin{gathered}
2 \mathrm{p}_{\mathrm{A}}=\frac{1}{\mathrm{E}(\theta)}+\mathrm{p}_{\mathrm{B}}-\frac{\delta \mathrm{V} \psi}{\mathrm{E}(\theta)} \quad 2 \mathrm{p}_{\mathrm{B}}=\frac{1}{\mathrm{E}(\theta)}+\mathrm{p}_{\mathrm{A}}+\frac{\delta V \psi}{\mathrm{E}(\theta)} \\
\text { or }\left\{\begin{array}{l}
\mathrm{p}_{\mathrm{A}}=\frac{1}{\mathrm{E}(\theta)}-\frac{1}{3} \frac{\delta V}{\mathrm{E}(\theta)} \frac{\Delta \theta}{\bar{\varepsilon}} \\
\mathrm{p}_{\mathrm{B}}=\frac{1}{\mathrm{E}(\theta)}+\frac{1}{3} \frac{\delta V}{\mathrm{E}(\theta)} \frac{\Delta \theta}{\bar{\varepsilon}}
\end{array}\right.
\end{gathered}
$$

And the symmetric equilibrium

$$
\left\{\begin{array}{l}
\mathrm{p}_{\mathrm{A}}=\frac{1}{\mathrm{E}(\theta)}+\frac{1}{3} \frac{\delta \mathrm{V}}{\mathrm{E}(\theta)} \frac{\Delta \theta}{\overline{\bar{\varepsilon}}} \\
\mathrm{p}_{\mathrm{B}}=\frac{1}{\mathrm{E}(\theta)}-\frac{1}{3} \frac{\delta \mathrm{V}}{\mathrm{E}(\theta)} \frac{\Delta \theta}{\bar{\varepsilon}}
\end{array}\right.
$$

In the example of section II $\frac{1}{3} \frac{\delta V}{E(\theta)} \frac{\Delta \theta}{\bar{\varepsilon}}=\frac{\delta}{18}$. 


\section{Appendix B (Section III.a)}

\section{Proof of proposition 3}

We assume $1.0 . \mathrm{g}$. that $\mathrm{q}_{0}=\frac{1}{2}$ to simplify notations. Let us denote

$$
\left\{\begin{array}{l}
\bar{x}=\Delta D_{A}+\Delta D_{B} \\
\bar{y}=\Delta D_{A}-\Delta D_{B}
\end{array}\right.
$$

When $p_{A}=p_{B},|\bar{y}|$ is at its minimal value $\bar{y}=0$ while for $p_{A} \neq p_{B}$ but close, $\bar{y}$ is different then 0 but close. The posterior probability of $\theta=\underline{\theta}$ when the firms observe

$$
\left\{\begin{array}{l}
\tilde{X}_{A}=D\left(p_{A}, p_{B}, \underline{\theta}\right)+x+y \\
\tilde{X}_{B}=D\left(p_{A}, p_{B}, \underline{\theta}\right)+x-y
\end{array}\right.
$$

is given by : $q=\frac{\mu(x, y)}{\mu(x, y)+\mu(x-\bar{x}, y-\bar{y})}$.

Consider a convex function $\pi$ and note $\tilde{\pi}(\bar{y})=E\{\pi(q) \mid \bar{x}, \bar{y}\}$

$\tilde{\pi}(\bar{y})=\int_{x} \int_{y} \pi(q)\{\mu(x, y)+\mu(x-\bar{x}, y-\bar{y})\} d y d x$

By symmetry : $\tilde{\pi}(\bar{y})=\tilde{\pi}(-\bar{y})$.

When differentiating

$$
\begin{aligned}
\tilde{\pi}(\bar{y})= & \int_{x} \int_{y}-\frac{1}{2} \mu_{2}(x-\bar{x}, y-\bar{y})\left\{\pi(q)-q \pi^{\prime}(q)\right\} d y d x \\
= & \int_{x} \int_{y}-\frac{1}{2} \frac{d}{d y}(\pi(q)\{\mu(x, y)+\mu(x-\bar{x}, y-\bar{y})\}) d y d x \\
& +\int_{x} \int_{y} \mu_{2}(x, y)\left\{\pi(q)+(1-q) \pi^{\prime}(q)\right\} d y d x
\end{aligned}
$$

We denote $g(q)=\pi(q)+(1-q) \pi^{\prime}(q)$, then

$\tilde{\pi}^{\prime}(\bar{y})=\int_{x} \int_{y} \mu_{2}(x, y) g(q) d y d x$

As $\mu$ is symmetric with $y$ and $\mu_{2}(x, y)$ is antisymmetric :

$\tilde{\pi}^{\prime}(\bar{y})=\int_{x} \int_{y>0} \mu_{2}(x, y)\left\{g\left[\frac{\mu(x, y)}{\mu(x, y)+\mu(x-\bar{x}, y-\bar{y})}\right]-g\left[\frac{\mu(x, y)}{\mu(x, y)+\mu(x-\bar{x}, y+\bar{y})}\right]\right\} d y d x$

Consider $\bar{y}>0$ and $y>0$, as $-y-\bar{y}<y-\bar{y}<y+\bar{y}$ and $\mu$ is symmetric quasi-concave with $\mathrm{y}$ :

$$
\mu(x-\bar{x}, y-\bar{y}) \geqslant \mu(x-\bar{x}, y+\bar{y})
$$


As $g$ is increasing and $\mu_{2}(x, y) \leqslant 0$ for $y>0$ we obtain $\tilde{\pi}^{\prime}(\bar{y}) \geqslant 0$ for $\bar{y}>0$.

When $(\bar{x}, 0)$ is not fully informative, $\mu(x-\bar{x}, y-\bar{y}) \neq \mu(x-\bar{x}, y+\bar{y})$ and $\mu_{2}(x, y) \neq 0$ must occur on a set of positive measure so that $\tilde{\pi}(\bar{y})$ is at a strict minimum at $\overline{\mathrm{y}}=0$.

\section{Appendix B (Section III.b)}

$$
\text { Q.E.D. }
$$

\section{The N-firms case}

The basic payoff of firm $n$ is

$\left[\frac{1}{N}+\theta\left(\frac{p_{n-1}+p_{n+1}}{2}-p_{n}\right)\right] p_{n}$ where $p_{n-1}$ and $p_{n+1}$ are adjacent firms' prices and $p_{n}$ is firm $n$ price.

By a reasoning similar to the reasoning in section II firm $\mathrm{n}$ learn the value of $\theta$ with probability $\alpha_{n}=\min \left\{1, N \frac{\Delta \theta}{\bar{\varepsilon}}, \frac{p_{n-1}+p_{n}}{2}-p_{n} \mid\right\}$ when its immediate rivals have set prices $p_{n-1}$ and $p_{n+1}$ in stage 1 and firm $n$ has set $p_{n}$. Notice that since the noises are independant the events $\{n$ learn $\theta$ \} and $\{m$ learn $\theta\}$ are independant for two firms $m$ and $n$. It follows that firm $n$ relevant information in period 2 consists in its own information about $\theta$ and $\alpha=\left\{\alpha_{1} \ldots \alpha_{N}\right\}$ the probabilities that each firm learn $\theta$.

The period 2 equilibrium will consist in 3 sets of prices, function of $\alpha$ :

$$
\begin{cases}\bar{p}_{n}(\alpha) & \text { price of firm } n \text { if it knows } \theta=\bar{\theta} \\ p_{n}(\alpha) & \text { price of firm } n \text { if it knows } \theta=\underline{\theta} \\ p_{n}(\alpha) & \text { price of firm } n \text { if it does not know } \theta\end{cases}
$$

These prices must verify :

$$
\begin{aligned}
& \bar{p}_{n}(\alpha)=\frac{1}{2 N} \frac{1}{\bar{\theta}}+\frac{1}{4} E\left\{p_{n-1}+p_{n+1} \mid \theta=\bar{\theta}, \alpha\right\} \\
& p_{n}(\alpha)=\frac{1}{2 N} \frac{1}{\theta}+\frac{1}{4} E\left\{p_{n-1}+p_{n+1} \mid \theta=\underline{\theta}, \alpha\right\} \\
& p_{n}(\alpha)=\frac{1}{2 N} \frac{1}{E(\theta)}+\frac{1}{4} E\left\{p_{n-1}+p_{n+1} \mid \alpha\right\}
\end{aligned}
$$


Let $\bar{p}=\left\{\bar{p}_{n}\right\}, p=\left\{p_{n}\right\}, p=\left\{p_{n}\right\}$, and denote $M_{N}(\alpha)$ the matrix :

and $e_{N}$ the unit vector, $M_{N}=M_{N}\left(e_{N}\right)$.

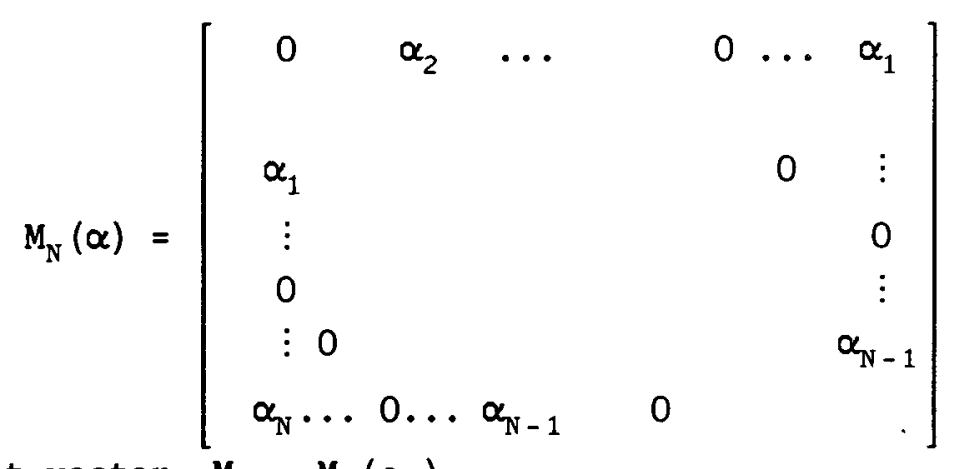

Then the equilibrium condition writes as a vectorial relation :

$$
\left\{\begin{array}{l}
\bar{p}(\alpha)=\frac{1}{2 N} \frac{1}{\bar{\theta}} e_{N}+\frac{1}{4} M_{N}(\alpha) \bar{p}(\alpha)+\frac{1}{4}\left[M_{N}-M_{N}(\alpha)\right] p(\alpha) \\
p(\alpha)=\frac{1}{2 N} \frac{1}{\underline{\theta}} e_{N}+\frac{1}{4} M_{N}(\alpha) p(\alpha)+\frac{1}{4}\left[M_{N}-M_{N}(\alpha)\right] p(\alpha) \\
p(\alpha)=\frac{1}{2 N} \frac{1}{E(\theta)} e_{N}+\frac{1}{4} \frac{M_{N}(\alpha)}{E(\theta)}\left\{q_{0} \underline{\theta} p(\alpha)+\left(1-q_{0}\right) \bar{\theta} \bar{p}(\alpha)\right\}+\frac{1}{4}\left[M_{N}-M_{N}(\alpha)\right] p(\alpha)
\end{array}\right.
$$

Combining the first two equations we obtain

$$
\frac{q_{0} \underline{\theta} p(\alpha)+\left(1-q_{0}\right) \bar{\theta} \bar{p}(\alpha)}{E(\theta)}=p(\alpha)
$$

Therefore $p(\alpha)=\frac{1}{E(\theta)} \frac{e_{N}}{N}$. This gives immediatly

$$
\begin{aligned}
& \bar{p}(\alpha)=\left(\operatorname{Id}_{N}-\frac{M_{N}(\alpha)}{4}\right)^{-1}\left(\frac{1}{2 \bar{\theta}}-\frac{1}{2 E(\theta)}\right) \frac{e_{N}}{N}+\frac{1}{E(\theta)} \frac{e_{N}}{N} \\
& p(\alpha)=\left(\operatorname{Id}_{N}-\frac{M_{N}(\alpha)}{4}\right)^{-1}\left(\frac{1}{2 \underline{\theta}}-\frac{1}{2 E(\theta)}\right) \frac{e_{N}}{N}+\frac{1}{E(\theta)} \frac{e_{N}}{N}
\end{aligned}
$$

Now let $\pi_{i}^{n}(\alpha)$ be the expected profits of firm $n$ conditional on the event that firm $n$ learn $\theta$.

Similarly let $\pi_{u}^{n}(\alpha)$ be the expected profits of firm $n$ conditional on $n$ does not learn $\theta$.

We see immediatly that $\pi_{u}^{n}(\alpha)=\frac{1}{N^{2}} \frac{1}{E(\theta)}=\pi_{u}$.

Now $\pi_{i}^{n}(\alpha)$ is given by $\pi_{i}^{n}(\alpha)=q_{0} \underline{\theta}_{p_{n}}(\alpha)^{2}+\left(1-q_{0}\right) \bar{\theta} \bar{p}_{n}(\alpha)^{2}$.

Let $v(\alpha)$ be the vector $\left[\operatorname{Id}_{N}-\frac{M_{N}(\alpha)}{4}\right]^{-1} e_{N}$. 
Then $\pi_{i}^{n}(\alpha)=q_{0} \underline{\theta}\left\{\frac{1}{E(\theta)}+\left(\frac{1}{2 \underline{\theta}}-\frac{1}{2 E(\theta)}\right) v_{n}(\alpha)\right\}^{2} \frac{1}{N^{2}}$

This solves as

$$
+\left(1-q_{0}\right) \bar{\theta}\left\{\frac{1}{E(\theta)}+\left(\frac{1}{2 \bar{\theta}}-\frac{1}{2 E(\theta)}\right) v_{n}(\alpha)\right\}^{2} \frac{1}{N^{2}}
$$

$$
\pi_{i}^{n}(\alpha)=\frac{1}{N^{2}} \frac{1}{E(\theta)}+\frac{1}{4 N^{2}}\left\{E\left(\frac{1}{\theta}\right)-\frac{1}{E(\theta)}\right\} v_{n}(\alpha)^{2}
$$

$\underline{\text { Lemma B.1 }}: \frac{1}{N^{2}}\left\{E\left(\frac{1}{\theta}\right)-\frac{1}{E(\theta)}\right\} \geqslant \pi_{i}^{n}(\alpha)-\pi_{u} \geqslant \frac{1}{4 N^{2}}\left\{E\left(\frac{1}{\theta}\right)-\frac{1}{E(\theta)}\right\}$.

Proof : This amounts to show that $2 \geqslant v_{n}(\alpha) \geqslant 1$. But $v(\alpha)=\sum_{s=0}^{\infty}\left(\frac{M_{N}(\alpha)}{4}\right)^{s} e_{N} \geqslant e_{N}$ so that $v_{n}(\alpha) \geqslant 1$. Now let $\bar{v}=\sup \left\{v_{n}(\alpha)\right\}$ then as $v(\alpha)=e_{N}+\frac{M_{N}(\alpha)}{4} e_{N}, \bar{v} \leqslant 1+\frac{1}{2} \bar{v}$ or $\bar{v} \leqslant 2$.

Q.E.D.

We can now go back to the period 1 game. Reduced payoff of firm $n$ is :

$p_{n}\left\{\frac{1}{N}+E(\theta) E\left(\frac{p_{n-1}+p_{n+1}}{2}-p_{n}\right)\right\}+\delta E \alpha_{n}\left\{\pi_{i}^{n}(\alpha)-\pi_{u}\right\}+\delta \pi_{u}$ with $\alpha_{n}=\min \left\{1, N \frac{\Delta \theta}{2}, \frac{p_{n-1}+p_{n+1}}{2}-p_{n} \mid\right\}$.

Let us denote $y_{n}=N p_{n}$. Then the payof $f$ is

$$
\begin{aligned}
\frac{1}{N^{2}} y_{n}\left\{1+E(\theta) E\left(\frac{y_{n-1}+y_{n+1}}{2}-y_{n}\right)\right\}+\delta E \alpha_{n}\left(\pi_{i}^{n}(\alpha)-\pi_{u}\right)+\delta \pi_{u} \\
\alpha_{n}=\min \left\{1, \frac{\Delta \theta}{\bar{\varepsilon}}\left|\frac{y_{n-1}+y_{n+1}}{2}-y_{n}\right|\right\}
\end{aligned}
$$

Let $F$ be a distribution symmetric around $\frac{1}{E(\theta)}$, then the best response set of firm $n$ when all other firms play according to $F$ is symmetric around $\frac{1}{E(\theta)}$ since $\mathrm{p}_{\mathrm{A}}=\frac{1}{\mathrm{E}(\theta)}-\varepsilon$ and $\mathrm{p}_{\mathrm{A}}=\frac{1}{\mathrm{E}(\theta)}+\varepsilon$ leads to the same payoff. It follows from this symmetry property and from the continuity of the payof function that there exists an equilibrium whose law is symmetric around $\frac{1}{E(\theta)}$. (The correspondance which associate to $F$ symmetric around $\frac{1}{E(\theta)}$ the set of best response distribution symmetric around $\frac{1}{\mathrm{E}(\theta)}$ is non-empty convex valued with closed graph). 
Let $F$ be this equilibrium distribution. Notice that as $v(\alpha)=\sum_{s=0}^{\infty}\left(\frac{M_{N}(\alpha)}{4}\right)^{s} e_{N}$, $\frac{d v(\alpha)}{d \alpha_{n}}>0$ for all $n$ and therefore $\frac{d \pi_{1}^{n}(\alpha)}{d \alpha_{m}}>0$ for $\alpha_{m}<1$.

Now suppose that $F$ has a mass point at some point $y$. Discontinuities in the derivative of $E \alpha_{n}\left(\pi_{i}^{n}(\alpha)-\pi_{u}\right)$ comes from the events $\frac{y_{n-1}+y_{n+1}}{2}=y$, $\frac{y_{n-2}+y}{2}=y_{n-1}$ and $\frac{y_{n+2}+y}{2}=y_{n+1}$ which occur with positive probability. In any of these events both an increase of $y_{n}$ from $y_{n}=y$ and a decrease in $y_{n}$ would lead to an increase in $\alpha_{n}, \alpha_{n-1}$ or $\alpha_{n+1}$ and therefore an increase in $\alpha_{n}\left[\pi_{1}^{n}\left(\alpha_{n}\right)-\pi_{u}\right]$. Therefore the right derivative of firm $n$ payoff at $\mathrm{y}_{\mathrm{n}}=\mathrm{y}$ must be higher than the left derivative which is impossible if $\mathrm{F}$ is an equilibrium. We conclude that the symmetric equilibrium distribution is continuous. Let $\left[\frac{1}{E(\theta)}-K(N), \frac{1}{E(\theta)}+K(N)\right]$ be its support. From the lemma $B .1$ the

$y_{n}\left\{2-E(\theta) y_{n}\right\}+\frac{\delta V}{4} E\left(\alpha_{n}\right)+\frac{\delta}{E(\theta)} \leqslant N^{2} \pi_{n}\left(y_{n}\right) \leqslant\left\{2-E(\theta) y_{n}\right\}+\delta V E\left(\alpha_{n}\right)+\frac{\delta}{E(\theta)}$ Suppose that $K(N)$ is very small. Then the equilibrium payoff $\pi_{n}\left(\frac{1}{E(\theta)}\right)$
verifies

$$
N^{2} \pi_{n}\left(\frac{1}{E(\theta)}\right) \leqslant \frac{1}{E(\theta)}(1+\delta)+\delta V \frac{\Delta \theta}{\bar{\varepsilon}} K(N)
$$
Suppose the firm deviates to $K(N) \leqslant y-\frac{1}{\mathrm{E}(\theta)} \leqslant \frac{\bar{\varepsilon}}{\Delta \theta}$, then the payoff it can
obtain verifies for the right choice of $\mathrm{y}^{\circ}$

$$
\mathrm{N}^{2} \pi_{\mathrm{n}}(\mathrm{y}) \geqslant \max _{\mathrm{y}} \mathrm{y}\{2-\mathrm{E}(\theta) \mathrm{y}\}+\frac{\delta \mathrm{V}}{4} \frac{\Delta \theta}{\bar{\varepsilon}}\left\{\mathrm{y}-\frac{1}{\mathrm{E}(\theta)}\right\}+\frac{\delta}{\mathrm{E}(\theta)}
$$

We see that if $K(N)$ is too small, $N^{2} \pi_{n}(y)>N^{2} \pi_{n}\left(\frac{1}{E(\theta)}\right)$ which is impossible. Therefore there exists $K>0$ such that $K(N) \geqslant K$ for all $N$. 


\section{Appendix C (section IV).}

\section{Proof of proposition 5}

Suppose that the game $G_{t-1}$ has a unique symmetric equilibrium. Let us denote $\pi_{u}^{t-1}$ the equilibrium profits in this game and $\pi_{i}^{t-1}=\frac{1}{2} E\left(\frac{1}{\theta}\right)\left(1+\delta+\ldots+\delta^{t}\right)$ the expected profits of firms if they learn $\theta$ before the game $G_{t-1}$ starts. The value of information at date $\tau$ is $V_{t-1}=\pi_{i}^{t-1}-\pi_{u}^{t-1}$. Suppose that $V_{t-1}>0$, then the game $G_{t}$ has a unique equilibrium obtained by applying the results of appendix A.2. This equilibrium depends on fixed parameters and $V_{t-1}$. If we can show that $V_{t}>0$ when $V_{t-1}>0$ the proposition will be proved.

With the notations of appendix A.2, the equilibrium profits can be calculated at $\mathrm{x}=-\mathrm{K}$. We then obtain :

$$
\pi=\frac{1}{2 E(\theta)}+\delta \pi_{u}+E(\theta)\left\{-\frac{K^{2}}{2}+\lambda E \min \left\{1, \frac{y+K}{\tau}\right\}\right\}
$$

A direct computation shows that :

$$
\pi=\frac{1}{2 E(\theta)}+\delta \pi_{u}+\delta V+E(\theta)\left\{\frac{\alpha^{2}}{8}-\frac{\tau^{2}}{8} N(N+2)-\frac{\tau \alpha}{4}(N+2)\right\}
$$

Let us denote $f(V)=E(\theta)\left\{-\frac{\alpha^{2}}{8}+\frac{T^{2}}{8} N(N+2)+\frac{T \alpha}{4}(N+2)\right\}$.

Then $\pi=\frac{1}{2 E(\theta)}+\delta \pi_{u}+\delta V-f(V)$

Applying this formula to our problem we obtain :

$\pi_{\mathrm{u}}^{\mathrm{t}}=\frac{1}{2 \mathrm{E}(\theta)}+\delta \pi_{\mathrm{u}}^{\mathrm{t}-1}+\delta \mathrm{V}_{\mathrm{t}-1}-\mathrm{f}\left(\mathrm{V}_{\mathrm{t}-1}\right)$

and $V_{t}=V_{0}+\delta \pi_{i}^{t-1}-\delta \pi_{u}^{t-1}-\delta V_{t-1}+f\left(V_{t-1}\right)$

or $V_{t}=V_{0}+f\left(V_{t-1}\right)$.

The fact that $v_{t}>0$ when $V_{t-1}>0$ follows from lemma 1 .

\section{Proof of lemma 1}

i) $f(v)$ is $c^{1}$ : Let $V_{N}$ be defined by $\frac{\delta V_{N}}{E(\theta)}=\tau^{2} \frac{N(N+1)(N+2)}{12}$, then for
$V_{N}<V<V_{N+1}$, the equilibrium is ${ }^{1}$ obtained and $V_{N}<V<V_{N+1}, \quad$ the $\quad$ equilibrium $\quad \begin{aligned} & \text { is }(\theta) \text { obtained } \\ & f^{\prime}(V)\end{aligned}=\left\{\frac{\tau}{4}(N+2)-\frac{\alpha}{4}\right\} \cdot \frac{4 \delta}{\tau(N+1)(N+2)}$

$$
f^{\prime \prime}(V)=-\frac{4 \delta^{2}}{E(\theta)} \frac{1}{(\tau(N+1)(N+2))^{2}}<0
$$

Thus $f$ is $C^{1}$, concave on any interval $] V_{N}, V_{N+1}[$ 


$$
\begin{aligned}
\lim _{V \rightarrow \mathrm{N}^{-}} f(V) & =E(\theta)\left\{\frac{\tau^{2}}{8}(N-1)(N+1)+\frac{\tau^{2}}{4}(N+1)-\frac{\tau^{2}}{8}\right\} \\
& =E(\theta) \frac{\tau^{2}}{8} N(N+2) \\
\lim _{V \rightarrow N_{N^{+}}} f(V) & =E(\theta) \frac{\tau^{2}}{8} N(N+2)
\end{aligned}
$$

So $f$ is continuous.

$$
\begin{aligned}
& \lim _{\mathrm{V} \rightarrow \mathrm{V}_{\mathrm{N}^{-}}} f^{\prime}(\mathrm{V})=\left\{\frac{\tau}{4}(\mathrm{~N}+1)-\frac{\tau}{4}\right\} \cdot \frac{4 \delta}{\tau(\mathrm{N}+1) \mathrm{N}}=\frac{\delta}{\mathrm{N}+1} \\
& \lim _{\mathrm{V} \rightarrow \mathrm{V}_{\mathrm{N}^{+}}} f^{\prime}(\mathrm{V})=\frac{T}{4}(\mathrm{~N}+2) \frac{4 \delta}{\tau(\mathrm{N}+1)(\mathrm{N}+2)}=\frac{\delta}{\mathrm{N}+1}
\end{aligned}
$$

So $f$ is $\mathrm{c}^{1}$, concave, increasing.

For $V$ very small, $N=0$ and $f(V)=E(\theta)\left\{\frac{\tau \alpha}{2}-\frac{\alpha^{2}}{8}\right\}$ which leads to $f(V)=\delta V-\frac{(\delta V)^{2}}{2 E(\theta)}$ which is positive.

Finally $f(V) / V \leqslant E(\theta) \frac{\tau^{2}}{8}(N+2)^{2} / V$, as $V \geqslant \frac{N(N+1)(N+2)}{12} \frac{E(\theta)}{\delta} \tau$ we have $f(V) / V \leqslant \frac{12}{8} \delta \frac{N+2}{N(N+1)} \underset{V \rightarrow+\infty}{\longrightarrow} 0$. 


\section{Appendix D (section VII)}

\section{$\underline{\text { Section VII.1 }}$}

Let the value of information $V_{0}$ be negative. Consider first a two-period game. The reduced expected payoff of firm $A$ in the first period is :

$$
\mathrm{p}_{\mathrm{A}}\left(\frac{1}{2}+\mathrm{p}_{\mathrm{B}}-\mathrm{p}_{\mathrm{A}}\right)-\frac{\delta}{\bar{\varepsilon}}\left|\mathrm{p}_{\mathrm{A}}-\mathrm{p}_{\mathrm{B}}\right|\left|\mathrm{v}_{0}\right|+\delta \pi_{\mathrm{u}}^{0} \text { if }\left|\mathrm{p}_{\mathrm{A}}-\mathrm{p}_{\mathrm{B}}\right|<\bar{\varepsilon}
$$

and $\mathrm{p}_{\mathrm{A}}\left(\frac{1}{2}+\mathrm{p}_{\mathrm{B}}-\mathrm{p}_{\mathrm{A}}\right)+\delta \pi_{1}^{0}$ otherwhise. One can easily show that for $p_{B} \epsilon\left[\frac{1}{2}-\frac{\delta}{\bar{\varepsilon}}\left|V_{0}\right|, \frac{1}{2}+\frac{\delta}{\bar{\varepsilon}}\left|V_{0}\right|\right]$ the best response of $p_{A}$ is $p_{A}=p_{B}$. The set of symmetric equilibria consists in all equilibria $p_{A}=p_{B}=p$ where $\mathrm{p} \in\left[\frac{1}{2}-\frac{\delta}{\bar{\varepsilon}}\left|\mathrm{V}_{0}\right|, \frac{1}{2}+\frac{\delta}{\bar{\varepsilon}}\left|\mathrm{V}_{0}\right|\right]$. Among these equilibria the best equilibrium for firms is $p_{A}=p_{B}=p^{1}$ where $p^{1}=\frac{1}{2}+\frac{\delta}{\bar{\varepsilon}}\left|V_{0}\right|$.

Profits are then $\pi_{u}^{1}=(1+\delta) \pi_{u}^{0}+\frac{\delta}{\bar{\varepsilon}}\left|V^{0}\right|$. The value of information in the two-period game if firms play $\mathrm{p}^{1}$ when uninformed is then :

$$
\mathrm{V}_{1}=(1+\delta) \mathrm{V}_{0}-\frac{\delta}{\bar{\varepsilon}} \mid \mathrm{V}^{0} \mathrm{I}=\left(1+\delta+\frac{\delta}{\bar{\varepsilon}}\right) \mathrm{V}_{0}<\mathrm{V}_{0}<0
$$

We can now extend this result for a T-period game.

Consider date $T$ where there remain $t+1$ periods to be played. Suppose that $V_{t-2}$ is negative. Then at date $\tau+1$ there is a continuum of MPBE $\mathrm{p}_{\mathrm{A}}=\mathrm{p}_{\mathrm{B}}=\mathrm{p}$ where $\mathrm{p} \in\left[\frac{1}{2}-\frac{\delta}{\bar{\varepsilon}}\left|\mathrm{V}_{\mathrm{t}-2}\right|, \frac{1}{2}+\frac{\delta}{\bar{\varepsilon}}\left|\mathrm{V}_{\mathrm{t}-2}\right|\right]$. For each of these equilibria, the value of information at date $\tau+1$ is $\mathrm{p} / 2-\pi_{0}^{i}+\delta \mathrm{V}_{\mathrm{t}-2}=\mathrm{V}_{\mathrm{t}-1}$. The best MPBE at date $\tau+1$ is $\mathrm{p}^{\tau+1}=\frac{1}{2}+\frac{\delta}{\bar{\varepsilon}}\left|\mathrm{V}_{\mathrm{t}-2}\right|$. The best symmetric MPBE at date $\tau$ if the equilibrium is $p$ at date $\tau+1$ is

$$
\left\{\begin{array}{l}
* \mathrm{p}^{\tau}=\frac{1}{2}+\frac{\delta}{\bar{\varepsilon}}\left|\mathrm{V}_{\mathrm{t}-1}\right| \text { if } \mathrm{V}_{\mathrm{t}-1}<0 \\
{ }^{*} \text { unique symmetric equilibrium if } \mathrm{V}_{\mathrm{t}-1}>0
\end{array}\right.
$$

Date $\tau$ profits are maximized when $\mathrm{p}^{\tau+1}=\frac{1}{2}+\frac{\delta}{\bar{\varepsilon}}\left|V_{\mathrm{t}-2}\right|$ which maximizes $\left|V_{t-1}\right|$. As this maximizes also period $\tau+1$ profits, this shows that the best symmetric MPBE of the T-period game is at each date $\tau$ : 


$$
\left\{\begin{array}{l}
\mathrm{p}_{\mathrm{A}}=\mathrm{p}_{\mathrm{B}}=\mathrm{p}^{\tau}=\frac{1}{2}+\frac{\delta}{\bar{\varepsilon}}\left|\mathrm{V}_{\mathrm{t}-1}\right| \text { and } \\
\mathrm{v}_{\mathrm{t}}=\left(1+\delta+\frac{\delta}{\bar{\varepsilon}}\right) \mathrm{v}_{\mathrm{t}-1}<\mathrm{v}_{\mathrm{t}-1}<0
\end{array}\right.
$$

This remains true as long as the whole market is served at each date, or $\mathrm{p}^{1}<\mathrm{R}-\frac{1}{2}$ which we assume. For the $\mathrm{T}$-period game, the best symmetric MPBE is therefore characterized by a sequence of prices :

$$
\mathrm{p}^{1}>\ldots>\mathrm{p}^{\tau} \ldots>\mathrm{p}^{\mathrm{T}}=\frac{1}{2}
$$

\section{Section VII.2}

Consider the following example :

$E(\theta)=1 ; \delta=1 ; \frac{\Delta \theta}{\bar{\varepsilon}}=2 ; V_{0}>0$ but small. The two period game has two asymmetric equilibria

$$
\left\{\begin{array}{lll}
\text { equilibrium a } & \mathrm{p}_{\mathrm{A}}=1-\frac{2 \mathrm{~V}_{0}}{3} & \mathrm{p}_{\mathrm{B}}=1+\frac{2 \mathrm{~V}_{0}}{3} \\
\text { equilibrium } \mathrm{b} & \mathrm{p}_{\mathrm{A}}=1+\frac{2 \mathrm{~V}_{0}}{3} & \mathrm{p}_{\mathrm{B}}=1-\frac{2 \mathrm{~V}_{0}}{3}
\end{array}\right.
$$

Profits for firm A are

and symmetrically for firm $B$.

$$
\begin{cases}\pi_{a}^{A}=1+\frac{V_{0}}{3}+\frac{8}{9} V_{0}^{2} & \text { at the equilibrium a } \\ \pi_{b}^{A}=1-\frac{v_{0}}{3}+\frac{8}{9} V_{0}^{2} & \text { at the equilibrium } b\end{cases}
$$

Expected informed profits for the 2-period game are :

$$
\pi^{1}=1+2 V_{0}
$$

Consider now a 3-period game, then there is a collusive equilibrium as follows :

Whenever firms are informed they play $p_{A}^{\tau}=p_{B}^{\tau}=\frac{1}{\theta}$ at date $\tau$, otherwhise, at date $\tau=1 \quad p_{A}^{1}=p_{B}^{1}=p^{c}$

at date $\tau=2$, if $p_{A}^{1}=p_{B}^{1}=p^{c}$ and $D_{A}^{1} \leqslant \frac{1}{2}$ equilibrium a

$$
\begin{aligned}
\text { if } p_{A}^{1}=p_{B}^{1}=p^{c} \text { and } D_{A}^{1}>\frac{1}{2} & & \text { equilibrium } b \\
\text { if } p_{B}^{1}=p^{c}, p_{A}^{1} \neq p^{c} & & \text { equilibrium } b \\
\text { if } p_{A}^{1}=p^{c}, p_{B}^{1} \neq p^{c} & & \text { equilibrium a } \\
\text { if } p_{A}^{1} \neq p^{c}, p_{B}^{1} \neq p^{c} & & \text { symmetric equilibrium }
\end{aligned}
$$


Profits at date $\tau=1$ for firm $A$ when firm $B$ plays $p_{B}^{1}=p^{c}$ are then

$$
\begin{aligned}
& \text { if } \mathrm{p}_{\mathrm{A}}^{1}=\mathrm{p}^{\mathrm{c}} \quad \frac{1}{2} \mathrm{p}^{\mathrm{c}}+1+\frac{8}{9} \mathrm{~V}_{0}^{2} \\
& \text { if } \quad p_{A}^{1} \neq p^{c} \quad p_{A}^{1}\left\{\frac{1}{2}+\frac{1}{2}\left(p^{c}-p_{A}^{1}\right)\right\}+\left(\pi^{i}-\pi_{a}^{A}\right) \min \left\{1,\left|p_{A}^{1}-p^{c}\right|\right\}+\pi_{a}^{A}
\end{aligned}
$$$$
\begin{gathered}
\text { Whenever } v_{0} \text { is small, } p^{c}=1+2 \sqrt{\frac{2}{3} v_{0}}-\frac{14}{3} v_{0}+\frac{16}{9} v_{0}^{2} \text { is an } \\
\text { rium value. Profits at this equilibrium are then }
\end{gathered}
$$
equilibrium value. Profits at this equilibrium are then $\pi^{c}=\frac{3}{2}+\sqrt{\frac{2}{3} V_{0}}-\frac{7}{3} V_{0}+\frac{16}{9} V_{0}^{2}$

Informed profits for the three-period game are $\pi_{3}^{i}=\frac{3}{2}+3 V_{0}$. For $V_{0}$ small enough we obtain $\pi^{c}>\pi_{3}^{i}$ and $V_{3}<0$. 